\title{
CAPACIDADE DE SUPORTE DE CARGA E UMIDADE CRÍTICA DE UM LATOSSOLO INDUZIDA POR DIFERENTES MANEJOS ${ }^{(1)}$
}

\author{
Cezar Francisco Araujo-Junior ${ }^{(2)}$, Moacir de Souza Dias Junior ${ }^{(3)}$, \\ Paulo Tácito Gontijo Guimarães ${ }^{(4)}$ \& Elifas Nunes Alcântara ${ }^{(4)}$
}

\begin{abstract}
RESUMO
Os diferentes manejos de plantas invasoras em lavouras cafeeiras têm promovido alterações estruturais aos solos, comprometendo a sua qualidade física. Assim, o conhecimento da capacidade de suporte de carga do solo sob diferentes sistemas de manejo de plantas invasoras é essencial para o manejo sustentável do solo de lavouras cafeeiras. Os objetivos deste estudo foram: (a) avaliar a influência da adoção, durante 30 anos, de diferentes sistemas de manejo de plantas invasoras na capacidade de suporte de carga de um Latossolo Vermelho distroférrico (LVdf) cultivado com cafeeiros e localizado na Fazenda da Epamig em São Sebastião do Paraíso, MG (Latitude de $20^{\circ} 55$ ' 00 " S e Longitude $47^{\circ} 07$ ' 10 " W); b) determinar a tensão máxima $\left(\sigma_{\max }\right)$ aplicada ao solo por um trator; e c) estabelecer as umidades volumétricas críticas $\left(\theta_{\text {crítica }}\right)$ para o tráfego de um trator. Os manejos de plantas invasoras avaliados foram: sem capina (SCAP); capina manual (CAPM); herbicida de pós-emergência (HPOS); roçadora (ROÇA); enxada rotativa (ENRT); grade (GRAD); e herbicida de pré-emergência (HPRE). Em cada sistema de manejo, 15 amostras indeformadas de solo foram coletadas aleatoriamente no centro das entrelinhas dos cafeeiros, nas profundidades de 0-3, 10-13 e 25-28 cm, totalizando 315 amostras. Em uma mata nativa (MATA) sob LVdf, adjacente à área de estudo, foram coletadas 15 amostras adicionais por profundidade, as quais serviram de
\end{abstract}

(1) Parte da Tese de Doutorado do primeiro autor apresentada ao Programa de Pós-Graduação em Ciência do Solo do Departamento de Ciência do Solo da Universidade Federal de Lavras - DCS/UFLA. Projeto Financiado pelo Consórcio Brasileiro de Pesquisa e Desenvolvimento do Café CBP\&D/Café. Recebido para publicação em dezembro de 2009 e aprovado em outubro de 2010 .

(2) Engenheiro Agrônomo, Mestre em Solos e Nutrição de Plantas, Doutor em Ciência do Solo. Pesquisador da Área de Solos do Instituto Agronômico do Paraná - IAPAR. Caixa Postal 48, CEP 86001-970 Londrina (PR). E-mails: cezar_araujo@iapar.br; cfaj@bol.com.br

(3) Engenheiro Agrícola, PhD in Crop and Soil Science, Professor Associado do Departamento de Ciência do Solo, UFLA. Bolsista CNPq. E-mail: msouzadj@dcs.ufla.br

(4) Engenheiro-Agrônomo, Dr. Pesquisador do Centro Tecnológico do Sul de Minas, Empresa de Pesquisa Agropecuária de Minas Gerais (CTSM/EPAMIG), Campus da UFLA. Caixa Postal 176, CEP 37200-000 Lavras (MG). E-mails: paulotgg@epamig.br; elifas@epamig.ufla.br 
referência dos atributos avaliados. Os equipamentos utilizados no manejo da lavoura

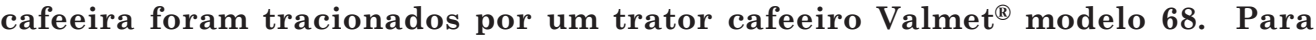
determinar a $\theta_{\text {crítica }}$ para o tráfego do trator, foram consideradas apenas aquelas tensões que não excedem a resistência interna do solo expressa pela pressão de preconsolidação. As amostras indeformadas foram utilizadas para determinar a pressão de preconsolidação $\left(\sigma_{p}\right)$ em diferentes umidades volumétricas $(\theta)$ e obtenção da densidade do solo (Ds). A partir do excedente das amostras indeformadas, foram determinados distribuição granulométrica de partículas, $\mathrm{C}$ orgânico do solo (COS) e teor de óxidos. Modelos de capacidade de suporte de carga (CSC) do tipo $\sigma_{\mathrm{p}}=10^{(\mathrm{a}+\mathrm{bq})}$ entre pressão de preconsolidação e umidade volumétrica foram obtidos para verificar os possíveis efeitos dos diferentes sistemas de manejo de plantas invasoras na estrutura do solo. A tensão máxima aplicada pelo trator cafeeiro foi de $220 \mathrm{kPa}$ para o pneu dianteiro 6-16 na pressão de inflação de $172 \mathrm{kPa}$. O menor valor de umidade crítica foi de $0,27 \mathrm{~cm}^{3} \mathrm{~cm}^{-3}$ para o LVdf sob o manejo SCAP na profundidade de 0$3 \mathrm{~cm}$, e o maior valor, de $0,48 \mathrm{~cm}^{3} \mathrm{~cm}^{-3}$ para o solo sob o manejo HPRE na profundidade de 0-3 cm. O manejo de plantas invasoras utilizando GRAD e HPRE favorece a formação do encrostamento superficial e os incrementos dos valores de densidade do solo e capacidade de suporte de carga na profundidade de $0-3 \mathrm{~cm}$. O solo sob MATA apresenta menor capacidade de suporte de cargas nas três profundidades estudadas, em relação ao solo cultivado com cafeeiros e submetido a diferentes manejos de plantas invasoras. Os diferentes manejos de plantas invasoras utilizadas no centro das entrelinhas da lavoura cafeeira não influenciaram a densidade do solo e o teor de C orgânico do Latossolo, na profundidade de $25-28 \mathrm{~cm}$, em relação ao solo sob mata nativa.

Temos de indexação: pressão de preconsolidação, distribuição de tensões, carbono orgânico do solo, umidade crítica, manejos de plantas invasoras; compactação do solo.

\section{SUMMARY: LOAD BEARING CAPACITY AND CRITICAL WATER CONTENT OF A LATOSSOL INDUCED BY DIFFERENT MANAGEMENTS}

Different weed managements in coffee have led to structural changes, affecting the soil physical quality. Therefore, information on the load bearing capacity of the soil under different weed managements is essential to establish a sustainable soil management under coffee. The objectives of this study were to: (a) assess the influence of different weed managements over three decades on the load bearing capacity of a Dystroferric Red Latosol (LVdf) cultivated with coffee on the Epamig Farm in São Sebastião do Paraíso, Minas Gerais State (Latitude de $20^{\circ} 55^{\prime} 00$ " $S$ and Longitude $47^{\circ} 07^{\prime} 10^{\prime \prime} \mathrm{W}$ ); (b) determine the maximum stress $\left(\sigma_{\max }\right)$ exerted by a tractor; $(c)$ establish the critical water content $\left(\theta_{\text {critica }}\right)$ for tractor traffic. The following weed managements were assessed: no weeding (SCAP); hand weeding (CAPM); post-emergence herbicide (HPOS); mowing (ROCAA); rotary tiller (ENRT); tandem disk harrow (GRAD) and pre-emergence herbicide (HPRE). In each management system 15 undisturbed soil samples were collected randomly in the coffee inter-rows in the layers $0-3,10-13$ and 25-28 cm, totaling 315 soil samples. Additionally, 15 samples per layer were collected in a native forest (MATA). The equipment used in coffee management was coupled to a Valmet ${ }^{\circledR}$ model 68 tractor for coffee. To determine $\theta_{\text {crítica }}$ for tractor traffic, only the stress was considered that did not exceed the internal strength of the soil expressed as precompression stress. The undisturbed soil samples were used to determine precompression stress $\left(\sigma_{p}\right)$ at different volumetric water contents $(\theta)$ and then bulk density $(B d)$. Disturbed samples were used to analyze particle size distribution, organic carbon (OC) and total oxides. Load bearing capacity (LBC) between precompression stress and volumetric water content was calculated $\left(\sigma_{p}=10^{(a+b \theta)}\right)$ to assess the possible effects of weed management systems on soil structure. The maximum stress caused by the Valmet ${ }^{\mathbb{B}}$ tractor (inflation pressure of the front tires 6 -16 of $172 \mathrm{kPa}$ ) was $220 \mathrm{kPa}$. The lowest critical water content was $0.27 \mathrm{~cm}^{3} \mathrm{~cm}^{-3}$ for the Dystroferric Red Latosol under no weeding in the $0-3 \mathrm{~cm}$ layer and the highest $0.48 \mathrm{~cm}^{3} \mathrm{~cm}^{-3}$ for the soil managed with pre-emergence herbicide in the 0-3 cm layer. The weed management with disk harrow and pre-emergence herbicide led to crusting on the soil surface and increased bulk density and precompression stress. The load bearing capacity of the soil under native forest was lower in the three layers studied compared to the soil under coffee and different weed managements. 


\begin{abstract}
The different weed managements used in the interrows did not influence soil bulk density and organic carbon content of Latossol, in the 25-28 cm layer, compared to the soil under native forest (MATA).
\end{abstract}

\begin{abstract}
Index terms: precompression stress; stress distribution; organic carbon; critical water content; weed management; soil compaction.
\end{abstract}

\section{INTRODUÇÃO}

O café é uma das principais commodities produzidas no Brasil, que é o país responsável pelo abastecimento de cerca de $30 \%$ do mercado mundial. O agronegócio café é um dos principais responsáveis pela geração de empregos, de renda e de desenvolvimento nas regiões de cultivo.

Minas Gerais é o principal Estado produtor brasileiro, respondendo por cerca de $50 \%$ da produção nacional. Lidera também os trabalhos de pesquisa, que resultam em novas tecnologias, logo incorporadas aos sistemas de produção (Corrêa et al., 2009), garantindo a eficiência, produtividade e qualidade do produto. Desse modo, vão sendo modernizadas as estruturas dos sistemas de produção e do manejo das lavouras, garantindo uma produção socialmente justa, ambientalmente sustentável, economicamente viável e culturalmente aceitável.

Os diferentes manejos de plantas invasoras têm promovido alterações estruturais nos solos cultivados com cafeeiros, alterando diversos atributos do solo, dentre os quais se destacam a densidade, a estabilidade de agregados em água e o teor de $\mathrm{C}$ orgânico do solo (Alcântara \& Ferreira, 2000), que podem influenciar no seu comportamento compressivo, aumentando o risco de compactação quando esses solos são trafegados por máquinas e implementos.

Alterações estruturais nas entrelinhas dos cafeeiros têm sido frequentes, sendo resultantes das operações de manejo de plantas invasoras e do tráfego eventual de máquinas (Kurachi \& Silveira, 1984; Alcântara \& Ferreira, 2000; Araujo-Junior et al., 2008; Gontijo et al., 2008). Essas alterações na estrutura do solo nas entrelinhas dos cafeeiros podem alterar a condutividade hidráulica do solo e as taxas de infiltração de água, durante as chuvas ou irrigação (Timm et al., 2005, 2006).

Herbicidas e capinas mecânicas são as práticas dominantes no controle de plantas invasoras, em muitos sistemas produtivos (Yang et al., 2007), inclusive em lavouras cafeeiras. Métodos mecânicos de controle de plantas invasoras, como a grade e a enxada rotativa, tendem a promover a compactação abaixo da profundidade de trabalho do equipamento, além de favorecer a erosão do solo pelo revolvimento intenso (Kurachi \& Silveira, 1984). Esse efeito é agravado quando o tráfego de máquinas e equipamentos é realizado em condições inadequadas de umidade e as tensões aplicadas ao solo excedem sua capacidade de suporte de carga, expressa pela pressão de preconsolidação (Dias Junior \& Pierce, 1996; Dias Junior, 2000; Horn et al., 2004; van den Akker \& Soane, 2005; Lebert et al., 2007).

A capacidade de suporte de carga é definida como a capacidade da estrutura do solo em resistir a tensões induzidas pelo tráfego de máquinas ou pisoteio animal, sem mudanças no arranjo tridimensional das partículas constituintes do solo (Alakukku et al., 2003), em uma determinada umidade ou potencial matricial.

Neste estudo, buscou-se definir a umidade volumétrica crítica para o tráfego de máquinas e equipamentos, na qual a capacidade de suporte de cargas do solo, expressa pela pressão de preconsolidação, é igual à tensão máxima exercida por um trator. Lebert et al. (2007) sugerem que a distribuição das tensões aplicadas pelas máquinas agrícolas seja determinada em duas umidades, nas suç̧ões de água $\mathrm{pF} 1,8=6 \mathrm{kPa}$ e $\mathrm{pF} 2,5=33 \mathrm{kPa}$, que representam dois níveis de capacidade de campo e o maior risco de compactação durante as operações agrícolas mecanizadas. Todavia, em qualquer condição de umidade e manejo, se as tensões aplicadas pelas máquinas e equipamentos ao solo forem maiores do que a pressão de preconsolidação, a probabilidade de o processo de compactação do solo ocorrer é grande, em decorrência da destruição da estrutura do solo (Kondo \& Dias Junior, 1999b).

De acordo com Kondo \& Dias Junior (1999b), o limite de plasticidade pode ser utilizado como a umidade máxima na qual as operações mecanizadas podem ocorrer. No entanto, esses autores ressaltam que se deve levar em consideração a aplicação das tensões exercidas pelos equipamentos.

Portanto, o entendimento de como o manejo de plantas invasoras influencia a capacidade de suporte de carga e o conhecimento dos níveis de pressões aplicados ao solo pelos equipamentos torna-se essencial para a adequação do manejo em lavouras cafeeiras. Diante dessas considerações, este estudo foi realizado com os objetivos de: avaliar a influência da adoção dos diferentes sistemas de manejo de plantas invasoras na capacidade de suporte de carga de um Latossolo Vermelho distroférrico (LVdf) em um experimento de longa duração; determinar a tensão máxima $\left(\sigma_{\text {máx }}\right)$ aplicada ao solo por um trator; e estabelecer as umidades volumétricas $\left(\theta_{\text {crítica }}\right)$ para o tráfego de um trator. 


\section{MATERIAL E MÉTODOS}

O estudo foi realizado no município de São Sebastião do Paraíso, na mesorregião Sul e Sudoeste de Minas Gerais, na latitude de $20^{\circ} 55^{\prime} 00$ " S e longitude de $47^{\circ} 07^{\prime} 10$ " W de Greenwich e a uma altitude de $885 \mathrm{~m}$. A região apresenta precipitação pluvial média anual de $1.470 \mathrm{~mm}$ e temperaturas média anual de $20,8^{\circ} \mathrm{C}$, média máxima de $27,6{ }^{\circ} \mathrm{C}$ e média mínima de $14,1^{\circ} \mathrm{C}$.

O solo da área de estudo e o da mata nativa são classificados como Latossolo Vermelho distroférrico típico (LVdf) (Embrapa, 2006) originado de basalto, textura argilosa e mineralogia gibbsítica (Quadro 1).

A área experimental foi plantada com cafeeiros da cultivar "Catuaí Vermelho" LCH 2077-2-5-99, no espaçamento de 4 x $1 \mathrm{~m}$, no ano de 1974 . O experimento foi instalado no ano de 1977, em delineamento experimental de blocos casualizados, com sete tratamentos e três repetições. Cada condição de manejo foi aplicada em três entrelinhas de $36 \mathrm{~m}$ de comprimento por 2,4 m de largura. As linhas de plantio foram mantidas sempre limpas, por meio de capina manual ou da aplicação de herbicidas.

Em 26 de dezembro de 2005, devido ao declínio de produção da lavoura implantada no ano de 1974, esta foi substituída por outra da cultivar Paraíso. A lavoura anterior foi retirada da área com o auxílio de um subsolador e, posteriormente, fez-se o sulcamento no mesmo local da linha de plantio anterior. Essas operações foram realizadas deixando intacto o efeito dos tratamentos ao longo dos anos nas entrelinhas.

Os teores de $\mathrm{SiO}_{2}, \mathrm{Al}_{2} \mathrm{O}_{3}, \mathrm{Fe}_{2} \mathrm{O}_{3}, \mathrm{TiO}_{2}$ e $\mathrm{P}_{2} \mathrm{O}_{5}$ foram determinados em amostras deformadas após digestão com $\mathrm{H}_{2} \mathrm{SO}_{4}\left(9,4 \mathrm{~mol} \mathrm{~L}^{-1}\right)$ (Embrapa, 1997).

Os índices de intemperismo $\mathrm{Ki}$ e $\mathrm{Kr}$ foram calculados pelas relações moleculares propostas por Resende \& Santana (1988).

A análise granulométrica foi realizada pelo método da pipeta (Day, 1965), utilizando como dispersante químico $10 \mathrm{~mL}$ de $\mathrm{NaOH}$ a $0,1 \mathrm{~mol} \mathrm{~L}^{-1}$ em contato com a amostra durante $24 \mathrm{~h}$; a dispersão mecânica foi realizada com a adição de $20 \mathrm{~g}$ de areia grossa e agitação lenta durante $4 \mathrm{~h}$ em agitador do tipo Wiegner com velocidade de 30 rotações/min (Grohmann \& Raij, 1977).
As operações de controle de plantas invasoras foram efetuadas quando se observava que aproximadamente $90 \%$ da área estava coberta pelas plantas invasoras e,ou, estas apresentavam $45 \mathrm{~cm}$ de altura (Alcântara \& Ferreira, 2000). Os manejos de plantas invasoras utilizados foram: (a) Sem capina (SCAP): as plantas invasoras foram deixadas em livre crescimento nas entrelinhas dos cafeeiros; (b) Capina manual (CMAN): realizada com o auxílio de uma enxada, sendo realizadas em média cinco operações anuais; (c) Herbicida de pós-emergência (HPOS): glyphosate alternadamente com glyphosate $+2,4-\mathrm{D}$, com média de três aplicações ao ano, entre os meses de outubro e abril; (d) Roçadora (ROÇA): o equipamento utilizado foi uma roçadora da marca Kamaq ${ }^{\circledR}$ modelo KD 132, com largura de corte de 1,32 e massa estática de $340 \mathrm{~kg}$; em média, foram realizadas cinco operações anuais; (e) Enxada rotativa (ENRT): com profundidade de trabalho de aproximadamente $10 \mathrm{~cm}$; em média, foram realizadas três operações anuais; (f) Grade (GRAD): composta de duas seções dispostas em tandem, com largura de corte de 1,3 m e massa estática de $300 \mathrm{~kg}$, com profundidade de trabalho de aproximadamente $7 \mathrm{~cm}$; em média, foram realizadas três operações anuais; e (g) Herbicida de pré-emergência (HPRE): Ametryn + Simazine para esta aplicação, cuidou-se para que o solo estivesse livre de restos culturais e plantas invasoras; em média, três aplicações ao ano, entre os meses de outubro e abril.

Todos os equipamentos utilizados no manejo da lavoura cafeeira foram tracionados por um trator marca Valmet ${ }^{\circledR}$ modelo 68 cafeeiro, massa de $3.900 \mathrm{~kg}$, peso de $38.245 \mathrm{~N}$, obtido pela expressão $(3.900 \mathrm{~kg}$ x 9,80665 $\left.\mathrm{m} \mathrm{s}^{-2}\right)$, pneus traseiros $12.4-\mathrm{R} 28(31,5 \mathrm{~cm}$ de largura por $71 \mathrm{~cm}$ de diâmetro na pressão de inflação $18 \mathrm{psi}=124 \mathrm{kPa}$ ) com carga de $1.365 \mathrm{~kg}$ e pneus dianteiros 6-16 (15,2 cm de largura por $41 \mathrm{~cm}$ de diâmetro na pressão de inflação $25 \mathrm{psi}=172 \mathrm{kPa}$ ) com carga de $683 \mathrm{~kg}$. Os bulbos de tensão e a tensão máxima exercida pelos diferentes rodados em diferentes condições do solo e profundidade de preparo foram obtidos por meio do programa Tyres/Tracks and Soil Compaction - TASC (Diserens, 2005).

Para determinar a umidade volumétrica crítica $\left(\theta_{\text {crítica }}\right)$ para o tráfego de máquinas e equipamentos, foram consideradas apenas aquelas tensões que podem causar compactação adicional ou modificar significativamente o estado inicial da estrutura do solo,

Quadro 1. Teores de óxidos totais extraídos pelo ataque sulfúrico e granulometria do Latossolo Vermelho distroférrico (LVdf)

\begin{tabular}{|c|c|c|c|c|c|c|c|c|}
\hline Uso & $\mathrm{SiO}_{2}$ & $\mathrm{Al}_{2} \mathrm{O}_{3}$ & $\mathrm{Fe}_{2} \mathrm{O}_{3}$ & $\mathbf{K i} \mathbf{i}^{(1)}$ & $\mathbf{K} \mathbf{r}^{(2)}$ & Argila & Silte & Areia \\
\hline & \multicolumn{8}{|c|}{$-\mathrm{g} \mathrm{kg}^{-1}$} \\
\hline Mata nativa & 78 & 250 & 260 & 0,53 & 0,32 & 600 & 200 & 200 \\
\hline Cafeeiros & 70 & 250 & 270 & 0,47 & 0,28 & 560 & 230 & 210 \\
\hline
\end{tabular}

(1) Ki: relação molecular $\mathrm{SiO}_{2} / \mathrm{Al}_{2} \mathrm{O}_{3}$ x 1,7. ${ }^{(2)} \mathrm{Kr}: 1,7 \times \mathrm{SiO}_{2} /\left[\mathrm{Al}_{2} \mathrm{O}_{3}+\left(\mathrm{Fe}_{2} \mathrm{O}_{3 \mathrm{x}}\right.\right.$ 0,6375)]. ${ }^{(3)}$ Média de três repetições. 
sendo consideradas como limite as tensões que não excedem a resistência interna do solo expressa pela pressão de preconsolidação.

Amostras de solo com estrutura indeformada foram coletadas entre as datas 17/12/2007 e 23/12/2007. Para cada parcela, foram coletadas 15 amostras indeformadas, distribuídas nas profundidades de 0 $3,10-13$ e $25-28 \mathrm{~cm}$ no centro das entrelinhas dos cafeeiros, totalizando 315 amostras [15 amostras x 3 profundidades x 7 sistemas de manejo de plantas invasoras]. Além da amostragem realizada na lavoura cafeeira, foram obtidas adicionalmente 45 amostras indeformadas [15 amostras x 3 profundidades] em uma mata nativa também sob um LVdf adjacente à área de estudo. As amostras indeformadas foram coletadas utilizando um amostrador de Uhland e anéis de alumínio de $2,50 \mathrm{~cm}$ de altura por $6,30 \mathrm{~cm}$ de diâmetro. Cinco amostras de cada tratamento foram mantidas em uma bandeja com água destilada até dois terços da altura, para que ocorresse a saturação delas, sendo esse ponto atingido em média após $24 \mathrm{~h}$. $\mathrm{O}$ restante das amostras de cada tratamento foi seco ao ar em laboratório, para o equilíbrio em diferentes umidades volumétricas. Em seguida, foram submetidas ao ensaio de compressão uniaxial (Bowles, 1986; Dias Junior, 1994) nas pressões crescentes de $25,50,100,200,400,800$ e $1.600 \mathrm{kPa}$, em consolidômetro Durham Geo Slope Indicator ${ }^{\circledR}$ modelo S-450 Terraload. Cada pressão foi aplicada até obter 90 \% da deformação máxima (Taylor, 1948). Após a liberação da pressão, as amostras foram secas em estufa a $105-110^{\circ} \mathrm{C}$, por $24 \mathrm{~h}$, determinando-se a massa seca do solo e a densidade deste, que foi calculada de acordo com Blake \& Hartge (1986).

O valor de densidade do solo para o qual o LVdf estaria compactado - e considerado crítico para o desenvolvimento adequado dos cafeeiros - foi obtido a partir da curva de compressão do solo das amostras do solo sob mata nativa na profundidade de $25-28 \mathrm{~cm}$ e pode ser calculado conforme Equação 1.

$$
D s \sigma_{p}=D s i+10 \% D s i
$$

em que $\mathrm{Ds}_{\mathrm{p}}$ e Dsi são os valores da densidade do solo na pressão de preconsolidação e densidade inicial $\left(\mathrm{Mg} \mathrm{m}^{-3}\right)$ e $10 \%$ foi a diferença média entre os valores de Dsi e Dsøp para o LVdf.

Os teores de C orgânico do solo (COS) foram determinados pelo método da combustão via úmida, com oxidação do $\mathrm{C}$ orgânico com $5 \mathrm{~mL}$ de $\mathrm{K}_{2} \mathrm{Cr}_{2} \mathrm{O}_{7}$ (dicromato de potássio) $0,167 \mathrm{~mol} \mathrm{~L}^{-1}$ e $10 \mathrm{~mL} \mathrm{de}_{2} \mathrm{SO}_{4}$ (ácido sulfúrico) concentrado (Walkley \& Black, 1934).

A pressão aplicada às amostras indeformadas versus a densidade do solo foram utilizadas para a construção das curvas de compressão do solo, em que, no eixo das abscissas $(\mathrm{X})$, colocou-se a pressão aplicada em escala logarítmica e no eixo das ordenadas (Y) a densidade do solo (Larson et al., 1980) para determinação da pressão de preconsolidação $\left(\sigma_{p}\right)$ para cada amostra, utilizando-se o método proposto por Dias Junior \& Pierce (1995). Os valores de pressão de preconsolidação $\left(\sigma_{p}\right)$ com os valores de umidade volumétrica $(\theta)$ foram ajustados a uma regressão exponencial decrescente do tipo $\left[\sigma_{p}=10^{(a+b \theta)}\right]$ (Dias Junior, 1994). As letras "a" e "b" representam os parâmetros empíricos de ajuste do modelo, ou seja, o coeficiente linear e angular, respectivamente.

As comparações entre os modelos foram feitas utilizando o teste de homogeneidade de modelos lineares descrito em Snedecor \& Cochran (1989). Para obtenção dos modelos lineares a partir do modelo exponencial $\left[\sigma_{\mathrm{p}}=10^{(\mathrm{a}+\mathrm{b} \theta)}\right]$, aplicou-se o logaritmo nos valores de pressão de preconsolidação, resultando em uma equação do tipo $\log \sigma_{\mathrm{p}}=\mathrm{a}+\mathrm{b} \theta$. O teste de homogeneidade de modelos lineares considera dois modelos, e estes são comparados pela análise do intercepto "a", do coeficiente angular "b" e homogeneidade dos dados (F).

Os resultados das análises de densidade do solo e C orgânico do solo foram submetidos à análise de variância, considerando o delineamento experimental de blocos casualizados, em esquema de parcelas subdivididas como os manejos de plantas invasoras nas parcelas e profundidades nas sub-parcelas e a comparação das médias foi feita pelo teste de ScottKnott, utilizando-se o programa estatístico Sisvar (Ferreira, 2000).

\section{RESULTADOS E DISCUSSÃO}

Tanto as alterações nas densidades como as variações nos teores de C orgânico do LVdf sob mata nativa e cultivado com cafeeiros sob diferentes sistemas de manejo de plantas invasoras ocorreram principalmente na profundidade de 0-3 cm (Quadro 2).

Nas profundidades de $10-13 \mathrm{~cm}$ e $25-28 \mathrm{~cm}$, os valores de densidade do solo não foram diferentes entre os métodos de manejo de plantas invasoras (Quadro 2). Contudo, os valores de densidade obtidos para o solo sob lavoura cafeeira, na profundidade de $10-13 \mathrm{~cm}$, foram superiores aos encontrados para o solo sob mata nativa na mesma profundidade (Quadro 2). Os efeitos observados na Ds, na profundidade de 10-13 cm, são possivelmente decorrentes da implantação da lavoura cafeeira e do tráfego eventual de máquinas que ocorre no centro das entrelinhas dos cafeeiros.

Quanto à profundidade de 25-28 cm, os valores de densidade do solo não foram alterados pelos diferentes sistemas de manejo de plantas invasoras na lavoura cafeeira em relação ao solo sob mata nativa (Quadro 2), corroborando as observações de Alcântara \& Ferreira (2000), os quais observaram que as maiores influências do manejo de plantas invasoras em lavouras cafeeiras ocorrem até a profundidade de $15 \mathrm{~cm}$.

O valor de densidade crítico para o LVdf, calculado conforme a equação 1 , foi de $1,20 \mathrm{Mg} \mathrm{m}^{-3}$. Valor este, que corresponde ao valor de densidade do solo crítico sugerido por Dexter (2004) para a qualidade estrutural 
Quadro 2. Densidade do solo e teor de carbono orgânico de um Latossolo Vermelho distroférrico em três profundidades sob mata nativa e no centro das entrelinhas de cafeeiros submetidos a diferentes manejos de plantas invasoras

\begin{tabular}{|c|c|c|c|c|c|c|}
\hline \multirow{3}{*}{ Usos/manejo } & \multicolumn{3}{|c|}{ Densidade do solo $\left(\mathrm{Mg} \mathrm{m}^{-3}\right)$} & \multicolumn{3}{|c|}{ Carbono orgânico ( $\left.\mathrm{g} \mathrm{kg}^{-1}\right)$} \\
\hline & \multicolumn{6}{|c|}{ Profundidades (cm) } \\
\hline & 0-3 & $10-13$ & $25-28$ & $0-3$ & $10-13$ & $25-28$ \\
\hline Mata nativa (MATA) & $0,89 \mathrm{Aa}$ & $0,98 \mathrm{Ab}$ & $1,09 \mathrm{Ac}$ & $15,7 \mathrm{aC}$ & $12,8 \mathrm{bA}$ & $10,4 \mathrm{bA}$ \\
\hline Sem capina (SCAP) & $1,03 \mathrm{Ba}$ & $1,22 \mathrm{Bb}$ & $1,20 \mathrm{Ab}$ & $24,5 \mathrm{aA}$ & $14,3 \mathrm{bA}$ & $9,9 \mathrm{cA}$ \\
\hline Capina manual (CAPM) & $1,19 \mathrm{Ca}$ & $1,23 \mathrm{Ba}$ & $1,18 \mathrm{Aa}$ & $15,1 \mathrm{aC}$ & $11,0 \mathrm{bB}$ & $8,3 \mathrm{bA}$ \\
\hline Herb. pós-emergência (HPOS) & $1,18 \mathrm{Ca}$ & $1,27 \mathrm{Bb}$ & $1,17 \mathrm{Aa}$ & $16,8 \mathrm{aC}$ & $11,4 \mathrm{bB}$ & $8,3 \mathrm{cA}$ \\
\hline Roçadora (ROÇA) & $1,20 \mathrm{Ca}$ & $1,23 \mathrm{Ba}$ & $1,19 \mathrm{Aa}$ & $21,2 \mathrm{aB}$ & $12,8 \mathrm{bA}$ & $8,7 \mathrm{cA}$ \\
\hline Enxada rotativa (ENRT) & $1,11 \mathrm{Ca}$ & $1,23 \mathrm{Ba}$ & $1,15 \mathrm{Aa}$ & $20,3 \mathrm{aB}$ & $10,1 \mathrm{bB}$ & $8,5 \mathrm{bA}$ \\
\hline Grade (GRAD) & $1,30 \mathrm{Db}$ & $1,23 \mathrm{Ba}$ & $1,19 \mathrm{Aa}$ & $18,6 \mathrm{aB}$ & $10,1 \mathrm{bB}$ & $9,5 \mathrm{bA}$ \\
\hline Herb. pré-emergência (HPRE) & $1,34 \mathrm{Db}$ & $1,30 \mathrm{Bb}$ & $1,18 \mathrm{Aa}$ & $12,0 \mathrm{aD}$ & $9,3 \mathrm{bB}$ & $7,4 \mathrm{bA}$ \\
\hline
\end{tabular}

Médias seguidas da mesma letra minúscula nas linhas e maiúscula nas colunas, dentro de cada atributo, não diferem entre si a $5 \%$ pelo teste de Scott-Knott.

de solos argilosos de diferentes países. Reichert et al. (2003) sugerem que os valores de densidade do solo críticos ao desenvolvimento das plantas para solos muito argilosos variam de 1,25 a $1,30 \mathrm{Mg} \mathrm{m}^{-3}$. Portanto, o valor de $D_{s} \sigma_{p}$ pode ser indicado para determinar o valor de Ds crítico ao desenvolvimento adequado das plantas, destacando, no entanto, que o valor determinado pela equação 1 é mais restritivo que o valor determinado por Reichert et al. (2003). A Dsбp assumida como limite de degradação estrutural foi anteriormente discutida por Severiano et al. (2008). Estes autores observaram que no valor de densidade do solo, correspondente ao valor da pressão de preconsolidação (Dsøp), a porosidade de aeração e a resistência à penetração assumiram valores críticos ao desenvolvimento adequado de plantas para um Latossolo Vermelho-Amarelo.

Observa-se, pelo quadro 2, que os valores de Ds para o LVdf sob os manejos GRAD e HPRE apresentam-se excessivamente elevados na profundidade de 0-3 cm. Ambos os manejos (GRAD e HPRE) favorecem a desagregação da camada superficial pela ausência de cobertura permanente do solo, o que favorece o impacto direto das gotas de chuva, facilitando com isso a erosão e o encrostamento superficial. Este encrostamento varia de menos de $1 \mathrm{~mm}$ até $5 \mathrm{~cm}$ de espessura a partir da superfície do solo (Pagliai, 2007), sendo caracterizado por modificações específicas nessa superfície, devido à quebra dos agregados e ao entupimento dos poros (Faria et al., 1998; Pagliai, 2007). Como consequência desse processo, ocorre o entupimento e redução na continuidade dos poros, além de ele reduzir a condutividade hidráulica do solo saturado (Pagliai, 2007; Silva \& Kato, 1997) e aumentar os valores de densidade (Silva \& Kato, 1997) e resistência mecânica do solo expressa pela capacidade de suporte de carga (Araujo-Junior et al., 2008).

O teor de $\mathrm{C}$ orgânico do LVdf na profundidade de 0-3 cm sob o manejo SCAP apresentou valores mais elevados do que nos locais sob os demais sistemas de manejo de plantas invasoras e sob mata nativa (Quadro 2). A manutenção das plantas invasoras nas entrelinhas dos cafeeiros proporciona maior aporte de resíduos orgânicos para o solo sob o manejo sem capina, contribuindo para a elevação do teor de C orgânico (Alcântara \& Ferreira, 2000), além de constante cobertura vegetal do solo, o que reduz as taxas de decomposição da matéria orgânica. Por outro lado, o teor de C orgânico é reduzido para o LVdf sob o manejo HPRE na profundidade de 0-3 cm (Quadro 2), justificando os valores elevados de densidade do solo (Quadro 2) encontrados para o LVdf sob o manejo HPRE. Como a matéria orgânica apresenta menores valores de densidade do que as partículas minerais quando incorporadas à matriz do solo, a densidade do solo será reduzida, além de haver acréscimo na porosidade - efeito este conhecido como efeito de diluição (Soane, 1990). Portanto, o solo sob manejos de plantas invasoras que proporcionam o esgotamento do C orgânico do solo, como o HPRE, apresenta-se com valores elevados de densidade.

Os valores de tensões máximas calculados pelo programa TASC (Diserens, 2005) foram de 2,0 a 2,2 bar $=200$ a $220 \mathrm{kPa}$ para o pneu dianteiro 6-16 (variante 1, Figura 1a; e variante 3 , Figura 1 b) e de 1,2 a 1,4 bar $=120$ a $140 \mathrm{kPa}$ para o pneu traseiro $12.4-\mathrm{R} 28$ (variante 2, Figura 1b) e 2,0 a 2,2 bar $=200$ a $220 \mathrm{kPa}$ para o pneu traseiro 12.4-R28 (variante 4, Figura 1b).

Observa-se, na figura 1a,b, que a magnitude das tensões e as distribuições ao longo do perfil mudam com a alteração nas condições da superfície do solo. Além disso, a carga das rodas, $683 \mathrm{~kg}$ no pneu 6-16 (variantes 1 e 3 ) e $1.268 \mathrm{~kg}$ no pneu 12.4 R28 (variantes 2 e 4), e as áreas de contato, $381 \mathrm{~cm}^{2}$ (pneu 6-16) e $1.328 \mathrm{~cm}^{2}$ (pneu 12.4 R28), influenciam as distribuições das tensões (Figura 1a,b). Nota-se ainda que, com o aumento da profundidade e da distância do centro do pneu, as tensões normais (ou verticais) reduzem em grandeza, resultando possivelmente em menores deformações do solo em maiores profundidades, 
mas se estendem em áreas maiores (Cruz \& Saes, 1989; Smith et al., 2000).

As tensões máximas (200-220 kPa) são distribuídas até $12 \mathrm{~cm}$ de profundidade (Figura 1a,b). As tensões exercidas pelos rodados do trator podem causar compactação severa do solo nas profundidades de 15$16 \mathrm{~cm}$ (Figura 1b) e 16-21 cm (Figura 1b). Essa classificação foi feita considerando a mudança na estrutura abaixo da profundidade máxima de preparo do solo, a qual é mais ou menos irreversível e, segundo os critérios adotados pelo programa TASC, ameaça a fertilidade do solo ao longo do tempo (Diserens, 2005). Para solos argilosos, o programa considera alto o ris- co de compactação com tensões maiores que $90 \mathrm{kPa}$ na umidade correspondente à capacidade de campo.

Para os bulbos de tensão apresentados na figura 1a, as condições das superfícies do solo foram consideradas quando os manejos do solo não revolvem a superfície do solo (SCAP; HPOS; ROÇA; HPRE) e a tensão máxima de $220 \mathrm{kPa}$ é exercida até a profundidade de $12 \mathrm{~cm}$. Na figura 1b, as condições do solo foram consideradas em uma situação semelhante ao que pode ocorrer nas áreas com manejo de plantas invasoras (CAPM ENRT e GRAD) utilizando o revolvimento do solo regularmente e a tensão máxima de $220 \mathrm{kPa}$ é exercida até a profundidade de $15 \mathrm{~cm}$.

(a)

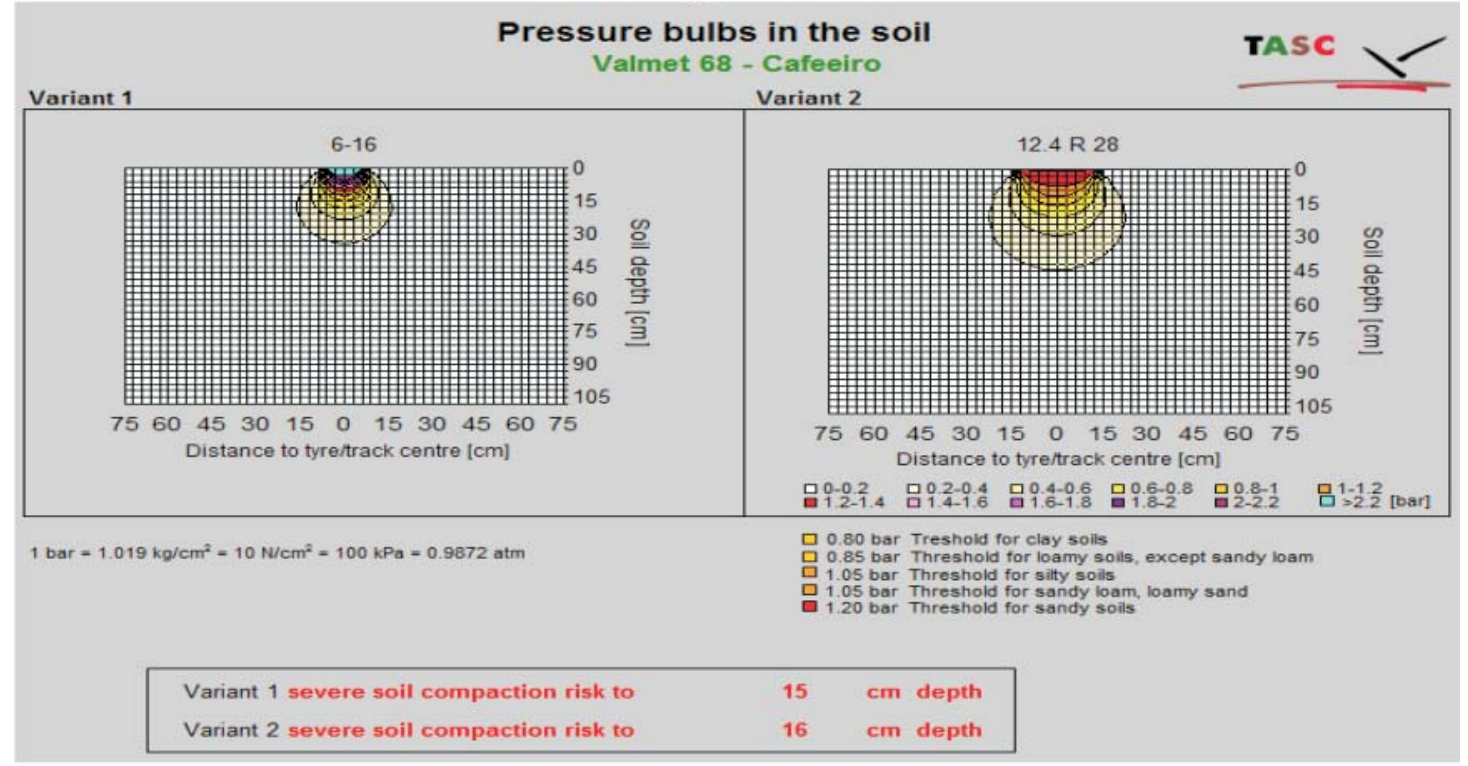

(b)

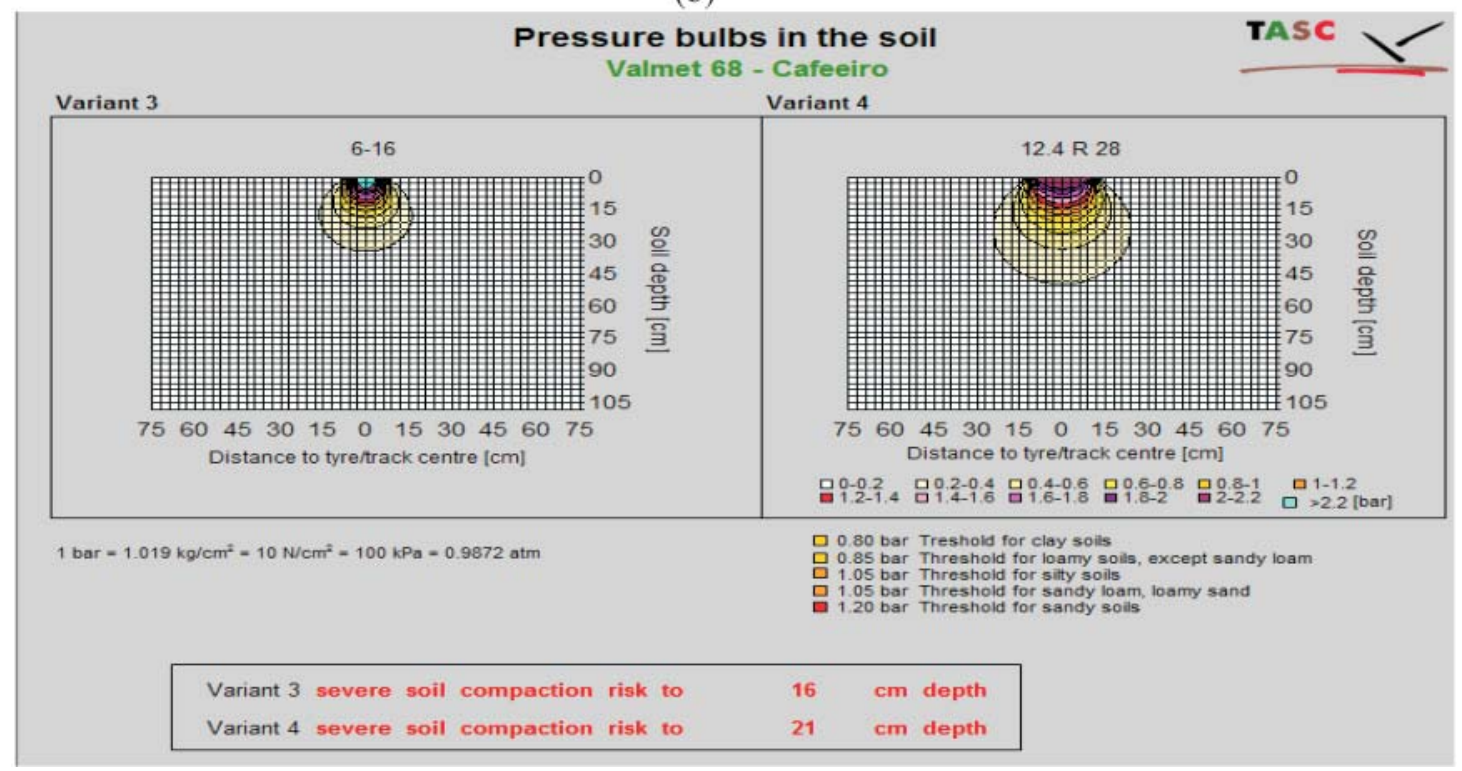

Figura 1. Bulbos de tensão obtidos para os pneus dianteiros 6-16 (variantes 1 e 3) e traseiros 12.4-R28 (variantes 2 e 4) do trator Valmet ${ }^{\circledR} 68$ cafeeiro, considerando o solo sem preparo (a) e o solo com preparo regular (b). 
Apesar de o programa TASC ser uma ferramenta importante para o manejo na prevenção da disseminação da compactação dos solos, esse modelo faz ainda um julgamento subjetivo do risco de compactação, uma vez que este não considera o comportamento compressivo dos solos sob diferentes sistemas de manejo. Assim, a fim de analisar o risco de compactação, foram utilizados os modelos de capacidade de suporte de carga do solo para estabelecer a umidade volumétrica do solo crítica para o tráfego do trator (Figuras 2 e 3 ).

Os coeficientes de determinação $\left(R^{2}\right)$ dos modelos de CSC foram todos significativos a $1 \%$ pelo teste tStudent e variaram de 0,49 a 0,92 (Quadro 3). O menor valor do coeficiente linear "a" encontrado para o LVdf sob o uso de mata nativa na profundidade de 0-3 cm pode estar associado ao menor empacotamento das partículas sólidas do solo, representado pelo menor valor de densidade do solo observado para esse uso nessa profundidade (Quadro 2). Esse resultado indica que um solo com menor história de tensão ou grau de compactação inicial apresenta menores valores do coeficiente linear. Menores valores do coeficiente linear dos modelos de CSC para diferentes solos sob mata nativa também foram observados por Kondo \& Dias Junior (1999a) e Silva \& Cabeda (2006).

Por outro lado, o maior valor do parâmetro "a" foi encontrado para o LVdf cultivado com cafeeiros sob o manejo de plantas invasoras roçadora na profundidade 10-13 cm, manejo que proporcionou valores de densidade do solo semelhantes aos dos demais sistemas de manejo de plantas invasoras nessa profundidade (Quadro 2), além de elevados teores de C orgânico (Quadro 2). Peng et al. (2004) observaram que o parâmetro "a" de um modelo exponencial, semelhante ao utilizado neste estudo, indica a resistência intrínseca do solo seco, e o parâmetro "b" descreve a influência e propriedades do solo, como textura e matéria orgânica, na resistência do solo. No entanto, neste estudo os parâmetros densidade do solo e C orgânico do solo influenciaram ambos os coeficientes dos modelos de CSC.

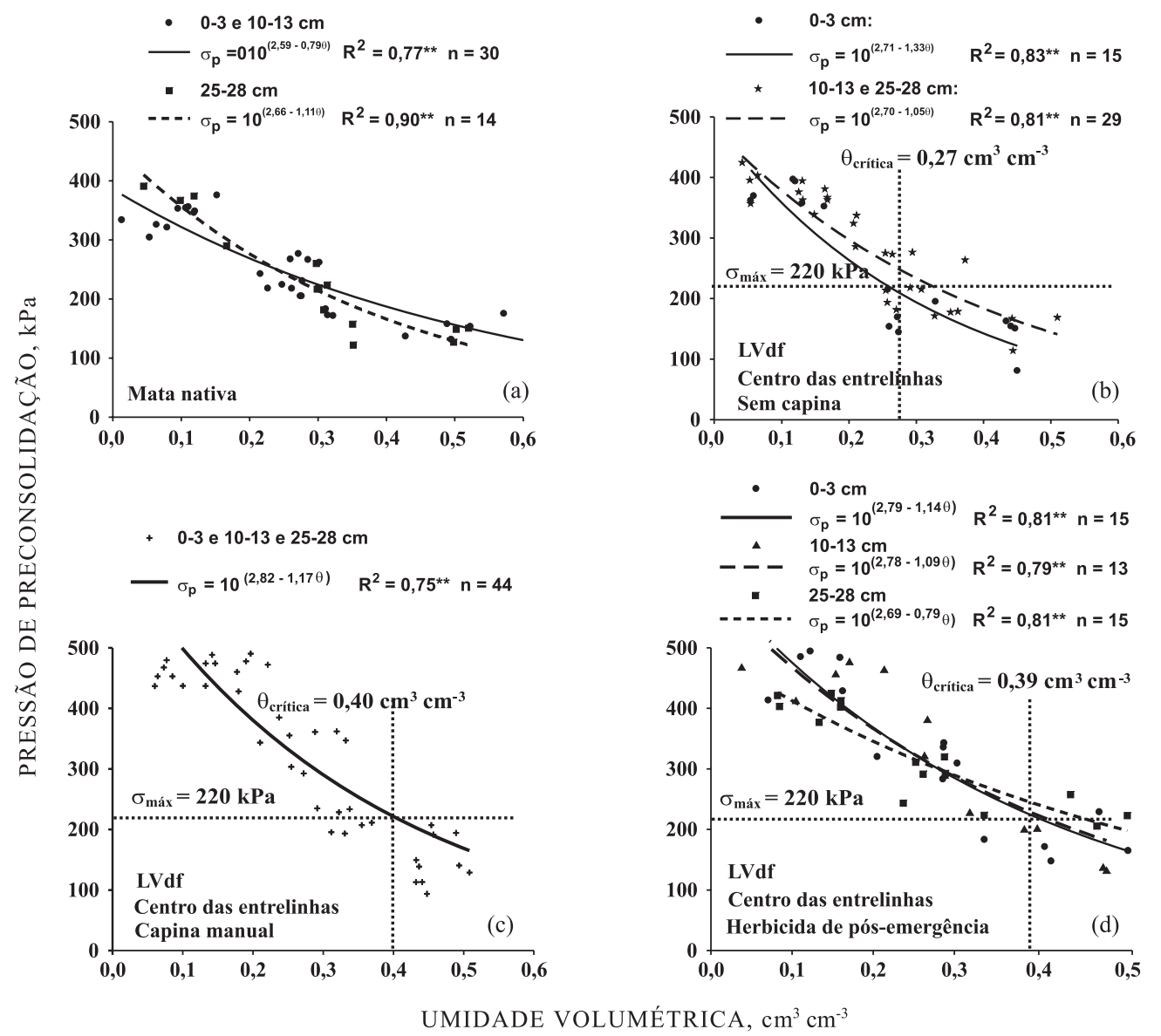

Figura 2. Modelos de capacidade de suporte de carga para um Latossolo Vermelho distroférrico (LVdf) sob mata nativa (a) e cultivado com cafeeiros sob os manejos de plantas invasoras sem capina (b), capina manual (c) e herbicida de pós-emergência (c) na posição de amostragem centro das entrelinhas dos cafeeiros em três profundidades. A linha pontilhada horizontal representa a tensão máxima de $220 \mathrm{kPa}$ $\left(\sigma_{\text {máx }}\right)$ aplicada pelo trator utilizado no manejo. As linhas pontilhadas verticais representam as umidades críticas $\left(\theta_{\text {crítica }}\right)$ para o tráfego do trator. 


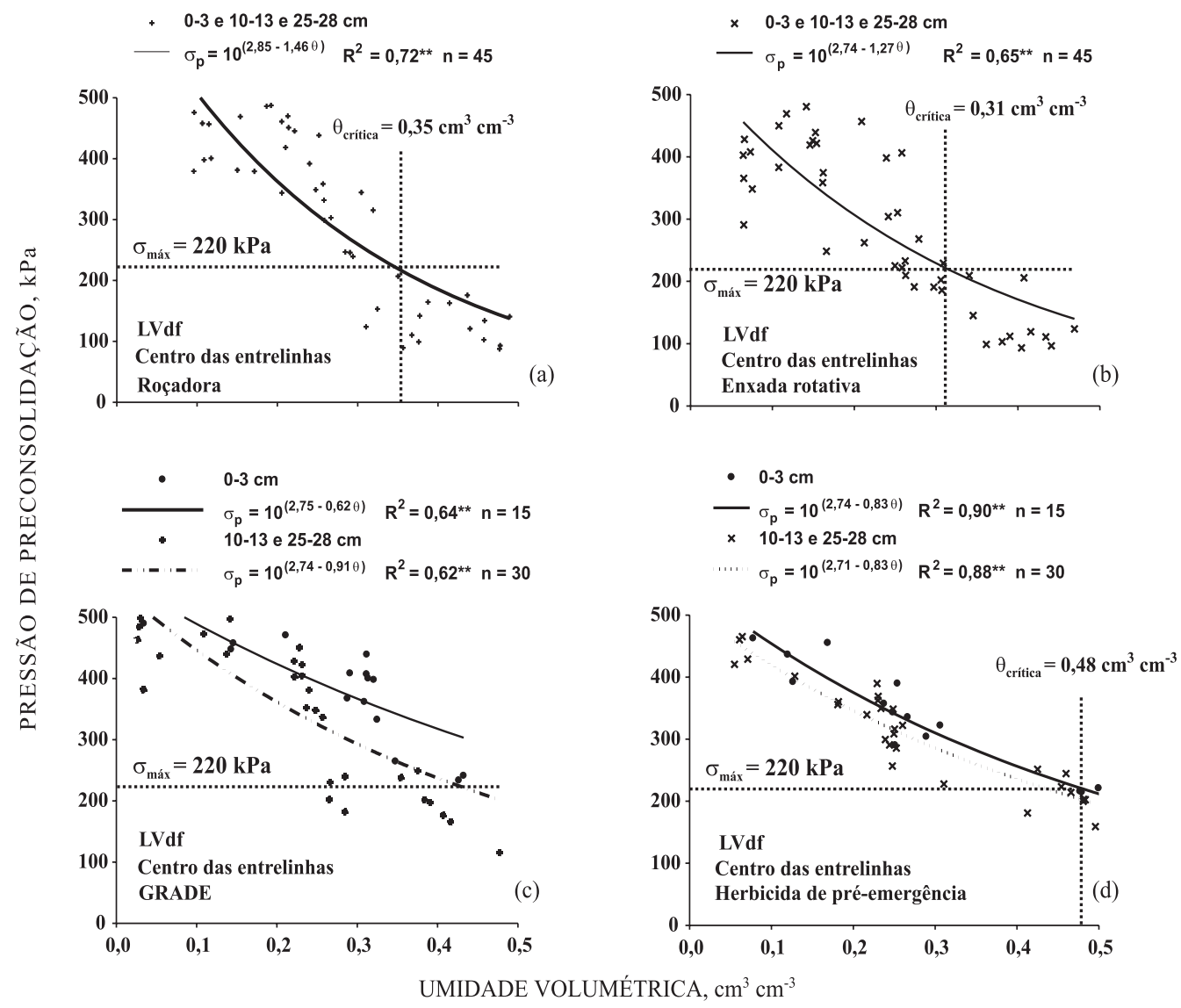

Figura 3. Modelos de capacidade de suporte de carga para um Latossolo Vermelho distroférrico (LVdf) sob mata nativa e cultivado com cafeeiros sob diferentes manejos de plantas invasoras na posição de amostragem centro das entrelinhas dos cafeeiros, em três profundidades. A linha pontilhada horizontal representa a tensão máxima de $220 \mathrm{kPa}\left(\sigma_{\text {máx }}\right)$ aplicada pelo trator utilizado no manejo. As linhas pontilhadas verticais representam as umidades críticas $\left(\theta_{\text {crítica }}\right)$ para o tráfego do trator.

Para verificar as possíveis alterações da estrutura do LVdf causadas pela lavoura cafeeira sob diferentes condições de manejo de plantas invasoras em relação à mata nativa, os modelos de CSC foram comparados utilizando o teste de homogeneidade de modelos lineares (Snedecor \& Cochran, 1989) nas diferentes profundidades, dentro de cada condição de manejo (Quadro 4). Os modelos de CSC obtidos para o LVdf nos manejos CAPM, ROÇA e ENRT não foram diferentes para as três profundidades (Quadro $4 \mathrm{e}$ Figuras 2c, 3a,b), ao passo que, para MATA e HPOS, os modelos CSC do LVdf não foram diferentes nas profundidades de 0-3 e 10-13 cm (Quadro 4 e Figura 2a,d). Para os manejos SCAP, GRAD e HPRE, os modelos de CSC do LVdf não foram diferentes nas profundidades de 10-13 e 25-28 cm (Quadro 4 e Figuras $2 b, 3 c, d)$. Para cada condição nas quais os modelos de CSC não foram diferentes, novas equações foram ajustadas, considerando todos os valores de pressão de preconsolidação $\left(\sigma_{\mathrm{p}}\right)$ e umidade volumétrica ( $\theta$ ) (Figuras 2 e 3 ).

$\mathrm{Na}$ figura 2a, observa-se maior CSC para o LVdf na profundidade de $25-28 \mathrm{~cm}$ até a umidade volumétrica de $0,22 \mathrm{~cm}^{3} \mathrm{~cm}^{-3}$, quando comparada às profundidades de $0-3$ e $10-13 \mathrm{~cm}$. Para valores de umidade superiores a $0,22 \mathrm{~cm}^{3} \mathrm{~cm}^{-3}$, observa-se inversão do comportamento quanto à CSC do solo. Os resultados obtidos quanto à CSC do LVdf sob MATA, neste estudo, foram semelhantes aos de Silva \& Cabeda (2006), quando esses autores observaram menor CSC de um solo sob mata nativa na profundidade de 0 $2 \mathrm{~cm}$, até umidade volumétrica de $0,20 \mathrm{~cm}^{3} \mathrm{~cm}^{-3}$. Na umidade de $0,27 \mathrm{~cm}^{3} \mathrm{~cm}^{-3}$, a CSC do solo sob mata nativa na profundidade de $0-2 \mathrm{~cm}$ foi superior à CSC na profundidade de 20-22 cm (Silva \& Cabeda, 2006).

$\mathrm{Na}$ figura $2 \mathrm{~b}$, observa-se que o manejo SCAP proporciona a menor CSC ao longo de todo o intervalo de umidade para a profundidade de $0-3 \mathrm{~cm}$. Essa menor CSC está associada aos menores valores de Ds (Quadro 2) e maiores conteúdos de COS (Quadro 2) nessa profundidade, em relação às profundidades de $10-13$ e $25-28 \mathrm{~cm}$. O maior conteúdo de COS na profundidade de $0-3 \mathrm{~cm}$ proporciona maior elasticidade ao solo. Com a liberação das tensões, o solo com maior conteúdo de $\mathrm{C}$ orgânico tende a ter maior resiliência ou recuperação da estrutura, 
Quadro 3. Coeficientes lineares e angulares dos modelos de capacidade de suporte de carga linearizados $\left[\log \sigma_{\mathrm{p}}=\mathrm{a}+\mathrm{b} \theta\right.$ ] de um Latossolo Vermelho distroférrico (LVdf) sob mata nativa e lavoura cafeeira na posição de amostragem centro das entrelinhas, em três profundidades e submetido a diferentes sistemas de manejo de plantas invasoras

\begin{tabular}{|c|c|c|c|c|}
\hline Manejo/Uso & a & $\mathbf{b}$ & $\mathbf{R}^{2}$ & $\mathbf{n}$ \\
\hline & \multicolumn{4}{|c|}{ Profundidade $0-3 \mathrm{~cm}$} \\
\hline Mata nativa & 2,57 & $-0,71$ & $0,80^{* *}$ & 15 \\
\hline Sem capina & 2,71 & $-1,33$ & $0,83^{* *}$ & 15 \\
\hline Capina manual & 2,82 & $-1,21$ & $0,79^{* *}$ & 14 \\
\hline Herbicida de pós-emergência & 2,79 & $-1,14$ & $0,81^{* *}$ & 15 \\
\hline Roçadora & 2,82 & $-1,26$ & $0,72^{* *}$ & 15 \\
\hline Enxada rotativa & 2,68 & $-1,18$ & $0,66^{* *}$ & 15 \\
\hline Grade & 2,75 & $-0,62$ & $0,64^{* *}$ & 15 \\
\hline \multirow[t]{2}{*}{ Herbicida de pré-emergência } & 2,74 & $-0,83$ & $0,90^{* *}$ & 15 \\
\hline & \multicolumn{4}{|c|}{ Profundidade $10-13 \mathrm{~cm}$} \\
\hline Mata nativa & 2,61 & $-0,90$ & $0,77^{* *}$ & 15 \\
\hline Sem capina & 2,71 & $-1,00$ & $0,86^{* *}$ & 14 \\
\hline Capina manual & 2,84 & $-1,22$ & $0,69^{* *}$ & 15 \\
\hline Herbicida de pós-emergência & 2,78 & $-1,09$ & $0,79^{* *}$ & 13 \\
\hline Roçadora & 2,91 & $-1,73$ & $0,79^{* *}$ & 15 \\
\hline Enxada rotativa & 2,76 & $-1,12$ & $0,62^{* *}$ & 15 \\
\hline Grade & 2,77 & $-1,00$ & $0,78^{* *}$ & 15 \\
\hline \multirow[t]{2}{*}{ Herbicida de pré-emergência } & 2,68 & $-0,77$ & $0,92^{* *}$ & 15 \\
\hline & \multicolumn{4}{|c|}{ Profundidade $25-28 \mathrm{~cm}$} \\
\hline Mata nativa & 2,66 & $-1,11$ & $0,90^{* *}$ & 14 \\
\hline Sem capina & 2,70 & $-1,15$ & $0,79^{* *}$ & 15 \\
\hline Capina manual & 2,78 & $-1,11$ & $0,80^{* *}$ & 15 \\
\hline Herbicida de pós-emergência & 2,69 & $-0,79$ & $0,81^{* *}$ & 15 \\
\hline Roçadora & 2,83 & $-1,43$ & $0,68^{* *}$ & 15 \\
\hline Enxada rotativa & 2,77 & $-1,48$ & $0,74^{* *}$ & 15 \\
\hline Grade & 2,71 & $-0,84$ & $0,49 * *$ & 15 \\
\hline Herbicida de pré-emergência & 2,73 & $-0,90$ & $0,88^{* *}$ & 15 \\
\hline
\end{tabular}

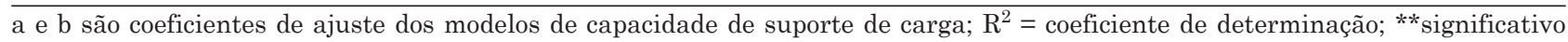
pelo teste de t-Student a $1 \% ; \mathrm{n}=$ número de amostras.

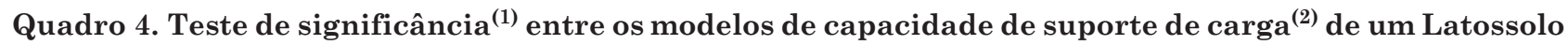
Vermelho distroférrico para os diferentes usos e manejo de plantas invasoras

\begin{tabular}{lllll}
\hline Usos/manejo de plantas invasoras & Profundidades $(\mathrm{cm})$ & F & F \\
\cline { 3 - 5 } & & & Coeficiente angular, b & Coeficiente linear, a
\end{tabular}

\begin{tabular}{|c|c|}
\hline Mata nativa & $\begin{array}{l}0-3 \times 10-13 \\
0-3 \text { e } 10-13 \times 25-28\end{array}$ \\
\hline Sem capina & $\begin{array}{l}0-3 \times 25-28 \\
10-13 \times 25-28 \\
0-3 \times 10-13 \text { e } 25-28\end{array}$ \\
\hline Capina manual & $\begin{array}{l}0-3 \times 10-13 \\
0-3 \text { e } 10-13 \text { × } 25-28\end{array}$ \\
\hline Herbicida de pós-emergência & $\begin{array}{l}0-3 \times 10-13 \\
0-3 \text { e } 10-13 \times 25-28\end{array}$ \\
\hline Roçadora & $\begin{array}{l}0-3 \times 10-13 \\
0-3 \text { e } 10-13 \text { × } 25-28\end{array}$ \\
\hline Enxada rotativa & $\begin{array}{l}0-3 \times 10-13 \\
0-3 \text { e } 10-13 \times 25-28\end{array}$ \\
\hline Grade & $\begin{array}{l}10-13 \times 25-28 \\
0-3 \times 10-13 \text { e } 25-28\end{array}$ \\
\hline Herbicida de pré-emergência & $\begin{array}{l}10-13 \times 25-28 \\
0-3 \times 10-13 \text { e } 25-28\end{array}$ \\
\hline
\end{tabular}

$\begin{array}{cl}n \mathrm{~ns} & \mathrm{~ns} \\ * & \mathrm{~ns} \\ \text { Centro das entrelinhas da lavoura cafeeira } \\ \mathrm{ns} & \mathrm{ns} \\ \mathrm{ns} & \mathrm{ns} \\ * & * * \\ \mathrm{~ns} & \mathrm{~ns} \\ \mathrm{~ns} & \mathrm{~ns} \\ \mathrm{~ns} & \mathrm{~ns} \\ * * & \mathrm{~ns} \\ \mathrm{~ns} & \mathrm{~ns} \\ \mathrm{~ns} & \mathrm{~ns} \\ \mathrm{~ns} & \mathrm{~ns} \\ \mathrm{~ns} & \mathrm{~ns} \\ \mathrm{~ns} & \mathrm{~ns} \\ \mathrm{~ns} & * * \\ \mathrm{~ns} & \mathrm{~ns} \\ \mathrm{~ns} & *\end{array}$

${ }^{(1)}$ Snedecor \& Cochran (1989). ${ }^{(2)} \sigma_{\mathrm{p}}=10^{(\mathrm{a}+\mathrm{b} \theta)}$; NH: não homogêneo; H: homogêneo; ** significativo a $1 \%$; *significativo a 5 \%; ns: não significativo. 
refletindo em menor resistência mecânica avaliada pelos modelos de CSC (Figura 2b) e menores valores de Ds (Quadro 2). O modelo de resiliência de solos com o aumento dos teores de matéria orgânica foi proposto por Zhang et al. (2005), indicando menores deformações plásticas ou irrecuperáveis e maior elasticidade para solos com elevados teores de matéria orgânica, fazendo com que o solo se comporte como uma mola.

Observa-se ainda na figura $2 \mathrm{~b}$ que, considerando a tensão máxima aplicada ao solo pelo trator $(220 \mathrm{kPa})$, o tráfego pode ser realizado sem promover a compactação adicional na profundidade de $0-3 \mathrm{~cm}$ até valores de umidade de $0,27 \mathrm{~cm}^{3} \mathrm{~cm}^{-3}$. Com o aumento da CSC nas profundidades de 10-13 e 25$28 \mathrm{~cm}$ ocorrerá compactação adicional somente se o tráfego for realizado em umidade volumétrica maior que $0,34 \mathrm{~cm}^{3} \mathrm{~cm}^{-3}$. No entanto, devem-se considerar as profundidades menos resistentes à compactação para que o tráfego de máquinas seja realizado, estabelecendo como limite o valor de $0,27 \mathrm{~cm}^{3} \mathrm{~cm}^{-3}$.

Para o manejo CAPM, a CSC foi igual nas três profundidades (Quadro 4 e Figura 2c). Esse comportamento possivelmente está associado à homogeneidade da densidade do solo nas três profundidades (Quadro 2), o que pode ser atribuído à influência do sistema radicular das plantas invasoras. No manejo CAPM, o tráfego do trator pode ser realizado sem promover a compactação adicional até a umidade volumétrica de $0,40 \mathrm{~cm}^{3} \mathrm{~cm}^{-3}$. $\mathrm{O}$ aumento da umidade crítica para a compactação adicional no manejo CAPM em relação ao manejo SCAP pode estar associado ao maior valor de $\mathrm{Ds}\left(1,19 \mathrm{Mg} \mathrm{m}^{-3}\right) \mathrm{em}$ relação à Ds do LVdf sob o manejo $\operatorname{SCAP}\left(1,03 \mathrm{Mg} \mathrm{m}^{-3}\right)$ (Figura 1a). Apesar disso, vale ressaltar que no manejo SCAP ocorrem maiores conteúdos de matéria orgânica (Quadro 2), o que possivelmente proporciona maior compressibilidade, porém, maior resiliência do solo quando liberado as tensões (Zhang et al., 2005), já que a matéria orgânica é um componente da fase sólida do solo que não é plástico e proporciona o aumento da faixa de umidade para o manejo do solo (Zhang et al., 1997). Portanto, manejos que proporcionam aumentos nos conteúdos de COS tendem a apresentar menores CSC, porém podem reduzir a suscetibilidade à compactação pelo aumento da elasticidade do solo (Zhang et al., 1997, 2005; van den Akker \& Soane, 2005).

A maior CSC para o LVdf sob manejo HPOS foi observada nas profundidades de 0-3 e 10-13 cm até a umidade volumétrica de $0,25 \mathrm{~cm}^{3} \mathrm{~cm}^{-3}$ (Figura $2 \mathrm{~d}$ ). No manejo HPOS, o tráfego do trator cafeeiro pode ser realizado sem promover compactação adicional nas profundidades de $0-3$ e $10-13 \mathrm{~cm}$ até a umidade volumétrica de $0,39 \mathrm{~cm}^{3} \mathrm{~cm}^{-3}$. Na profundidade de 25-28 cm, o tráfego desse trator pode ser realizado até a umidade volumétrica de $0,44 \mathrm{~cm}^{3} \mathrm{~cm}^{-3}$, considerando a tensão máxima de $220 \mathrm{kPa}$. No entanto, deve-se ressaltar que com o aumento da profundidade os valores de tensão aplicados ao solo são reduzidos (Figura 1a,b).
Na figura 3a,b e no quadro 3, observa-se que a CSC do LVdf foi igual nas três profundidades quando submetido aos manejos ROÇA e ENRT. Esse resultado, possivelmente, pode ser atribuído à homogeneidade dos valores de Ds nas três profundidades para os dois sistemas de manejo (Quadro 2), homogeneizando a CSC. Para o solo submetido ao manejo com ROÇA a umidade crítica foi de $0,35 \mathrm{~cm}^{3} \mathrm{~cm}^{-3}$ (Figura 3a), e para o solo sob o manejo ENRT, de $0,31 \mathrm{~cm}^{3} \mathrm{~cm}^{-3}$ (Figura $3 \mathrm{~B}$ ). Quanto ao solo submetido ao manejo com ENRT, o revolvimento constante do solo e a desestruturação deste promovem redução da CSC e consequente redução no valor de umidade crítica para o manejo (Figura 3b), em comparação ao solo submetido ao manejo com a ROÇA (Figura 3a). A maior amplitude para se atingir a umidade crítica está associada à maior CSC encontrada no solo sob o manejo ROÇA, o que se deve ao número de operações necessárias por ano (cinco) para o controle satisfatório das plantas invasoras com a roçadora, como anteriormente observado por Kurachi \& Silveira (1984). Apesar da elevada CSC do LVdf sob o manejo ROÇA, esse manejo não proporcionou valores de $\mathrm{Ds}$ nocivos ao crescimento radicular (Quadro 2); portanto, espera-se que a elevação da CSC do LVdf sob esse manejo seja atribuída à estabilidade estrutural proporcionada por este, conforme observado por Kurachi \& Silveira (1984) e Alcântara \& Ferreira (2000). Esse aspecto favorece a trafegabilidade e a trabalhabilidade das máquinas na lavoura cafeeira, provavelmente devido à maior macroporosidade, à maior condutividade hidráulica do solo saturado e à drenagem interna. Além disso, espera-se que as raízes da cultura possam fazer uso dos macroporos contínuos para penetrar no solo profundamente, além de isso aumentar a resistência do solo à compactação, uma vez que os macroporos podem ser contrários à tensão normal (van den Akker $\&$ Soane, 2005).

Na figura 3c, observa-se que o manejo das plantas invasoras com GRAD promove maior CSC ao LVdf ao longo de todo o intervalo de umidade para a profundidade de 0-3 cm. A maior CSC na profundidade de 0 $3 \mathrm{~cm}$ deve-se à exposição do solo às chuvas de alta intensidade e formação do encrostamento, como foi observado no campo, e ao maior valor de Ds (Quadro 2) em relação às demais profundidades. Observa-se ainda pela figura 3c que, considerando a tensão máxima aplicada ao solo pelo trator $(220 \mathrm{kPa})$, o tráfego pode ser realizado sem promover a compactação adicional para a profundidade de $0-3 \mathrm{~cm}$, uma vez que a tensão aplicada ao solo por esse trator não ultrapassa os valores de CSC. Nas profundidades de 10-13 e 25-28 cm, o tráfego pode ser realizado sem promover compactação adicional até valores de umidade de $0,44 \mathrm{~cm}^{3} \mathrm{~cm}^{-3}$. A ampla faixa de conteúdo de água para atingir a umidade crítica deve-se à história de tensão ou ao elevado grau de compactação inicial observado pela densidade do solo (1,30 $\left.\mathrm{Mg} \mathrm{m}^{-3}\right)$ encontrado para o LVdf sob o manejo GRAD na profundidade de $0-3 \mathrm{~cm}$. 
Na figura 3d, visualiza-se que o solo sob o manejo HPRE apresenta maior CSC ao longo de todo o intervalo de umidade para a profundidade de $0-3 \mathrm{~cm}$; nota-se ainda que, considerando a tensão máxima de $220 \mathrm{kPa}$ aplicada pelo trator cafeeiro, a umidade crítica para essa profundidade é de $0,48 \mathrm{~cm}^{3} \mathrm{~cm}^{-3}$. Para as profundidades de 10-13 e 25-28 cm, o tráfego do trator pode ser realizado sem promover compactação adicional até valores de umidade de $0,44 \mathrm{~cm}^{3} \mathrm{~cm}^{-3}$ (Figura $3 \mathrm{~d}$ ).

A fim de verificar as possíveis alterações na CSC do LVdf causadas pelos diferentes manejos de plantas invasoras em relação ao solo sob mata nativa, os modelos de CSC foram comparados dentro de cada profundidade entre os diferentes usos e manejos (Quadros 5 a 7).

Observa-se, pelos dados do quadro 5, que os modelos de CSC do LVdf submetido aos manejos SCAP vs ENRT e CAPM vs ROÇA vs HPOS não foram diferentes na profundidade de $0-3 \mathrm{~cm}$. Assim, para cada situação, uma nova equação foi ajustada, considerando todos os valores de pressão de preconsolidação e umidade volumétrica (Figura 4). Dessa forma, observa-se que, de maneira geral, a CSC do LVdf na profundidade de $0-3 \mathrm{~cm}$ segue a ordem: GRAD $>$ HPRE $>$ CAPM $=$ ROÇA $=$ HPOS $>$ SCAP $=$ ENRT $>$ MATA (Figura 4).

Pela figura 4, observa-se maior CSC para o LVdf sob o manejo GRAD ao longo de todo o intervalo de umidade. Esse resultado deve-se à maior densidade inicial (1,30 $\left.\mathrm{Mg} \mathrm{m}^{-3}\right)$ do LVdf associado a conteúdos de C orgânico intermediários (Quadro 2), o que promove maior aproximação das partículas, aumentando a CSC do solo. Além disso, como

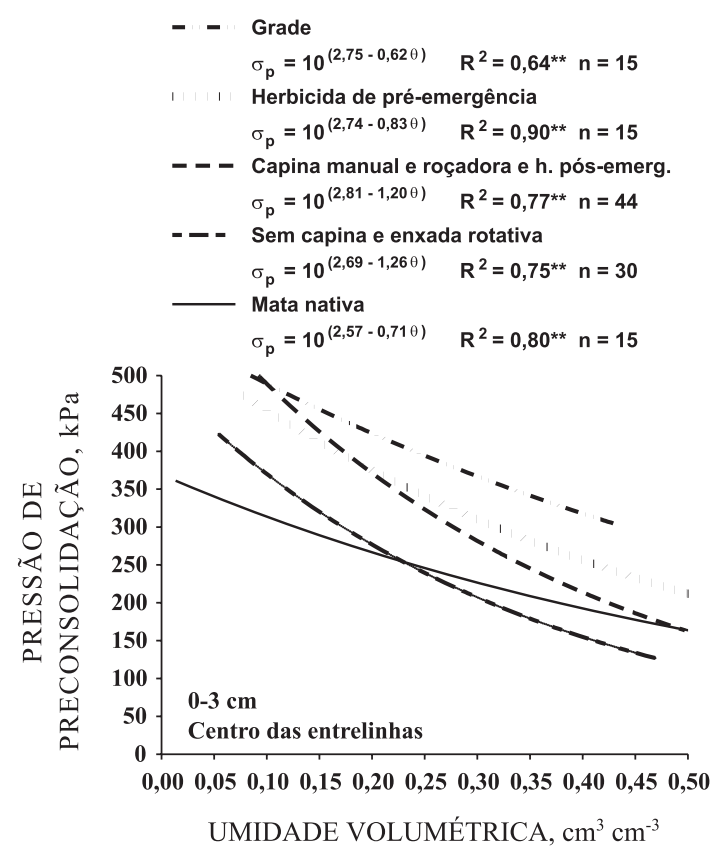

Figura 4. Modelos de capacidade de suporte de carga para um Latossolo Vermelho distroférrico sob mata nativa e cultivado com cafeeiros, submetido a diferentes sistemas de manejo de plantas invasoras na posição de amostragem centro das entrelinhas dos cafeeiros, na profundidade de $0-3 \mathrm{~cm}$.

ressaltado anteriormente, o fato de a largura de corte da grade $(1,30 \mathrm{~m})$ ser insuficiente para, em uma única passada, cobrir todo o centro das entrelinhas faz com que seja necessário maior quantidade de passadas para

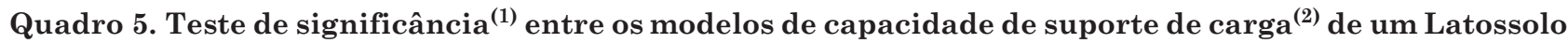
Vermelho distroférrico para os diferentes usos e manejo de plantas invasoras para a profundidade de 0$3 \mathrm{~cm}$, no centro das entrelinhas dos cafeeiros

\begin{tabular}{ccc} 
F & F \\
\cline { 2 - 3 } & $\begin{array}{c}\text { Coeficiente } \\
\text { angular, b }\end{array}$ & $\begin{array}{c}\text { Intercepto da } \\
\text { regressão, } \mathbf{a}\end{array}$
\end{tabular}

Sem capina $v s$ enxada rotativa

Sem capina e enxada rotativa $v s$ mata nativa

Sem capina e enxada rotativa $v s$ grade

Sem capina e enxada rotativa $v s$ herbicida de pré-emergência

Capina manual e roçadora us herbicida de pós-mergência

Capina manual e roçadora e herbicida de pós-emergência vs $\mathrm{S}$ herbicida de pré-emergência

Capina manual e roçadora e herbicida de pós-emergência us grade

Capina manual e roçadora e herbicida de pós-emergência vs mata nativa

Capina manual e roçadora e herbicida de pós-emergência vs sem capina

e enxada rotativa

Grade $v s$ herbicida de pré-emergência

Mata nativa us herbicida de pré-emergência

Mata nativa us grade
Capina manual us roçadora

\begin{tabular}{lcc} 
& \multicolumn{2}{c}{ Profundidade $0-3 \mathrm{~cm}$} \\
$\mathrm{H}$ & $\mathrm{ns}$ & $\mathrm{ns}$ \\
$\mathrm{NH}$ & $* *$ & $\mathrm{~ns}$ \\
$\mathrm{NH}$ & $*$ & $* *$ \\
$\mathrm{NH}$ & $*$ & $\mathrm{~ns}$ \\
$\mathrm{H}$ & $\mathrm{ns}$ & $\mathrm{ns}$ \\
$\mathrm{H}$ & $\mathrm{ns}$ & $*$ \\
$\mathrm{NH}$ & $* *$ & $* *$ \\
$\mathrm{H}$ & $* *$ & $*$ \\
$\mathrm{NH}$ & $* *$ & $* *$ \\
$\mathrm{H}$ & & \\
$\mathrm{NH}$ & $\mathrm{ns}$ & $\mathrm{ns}$ \\
$\mathrm{H}$ & $* *$ & $* *$ \\
$\mathrm{H}$ & $\mathrm{ns}$ & $* *$
\end{tabular}

(1) Snedecor \& Cochran (1989); ${ }^{(2)} \sigma_{\mathrm{p}}=10^{(\mathrm{a}+\mathrm{b} \theta)}$; NH: não homogêneo; H: homogêneo; **; *; ns: significativo a 1 e 5 \%; não significativo, respectivamente. 
um controle satisfatório das plantas invasoras, promovendo aumentos da densidade do solo (Quadro 2) e da CSC (Figura 4).

Outro aspecto que vale ressaltar é que, devido ao elevado grau de compactação proporcionado pelo manejo GRAD, foram observados sinais de erosão superficial, arrastando consigo a camada revolvida de solo. Kurachi \& Silveira, (1984) observaram quando o manejo de plantas invasoras foi realizado com a grade, em comparação ao manejo capina manual, aumentos na resistência mecânica na camada de 0 $30 \mathrm{~cm}$ de um Latossolo Vermelho distroférrico localizado em Analândia, SP. O manejo do solo utilizando a grade associado à elevada intensidade de tráfego também podem alterar a porosidade e a condutividade hidráulica do solo saturado, além da densidade do solo e da compressibilidade na camada superficial, como observado por Silva et al. (2003).

Os manejos GRAD e HPRE, os quais retiram a cobertura vegetal da área, favorecem o encrostamento superficial devido ao impacto direto das gotas de chuva (Kurachi \& Silveira, 1984; Faria et al., 1998; Alcântara \& Ferreira, 2000; Araujo Junior et al., 2008), o que pode explicar o aumento da CSC resultante do aumento do grau de compactação e maior aproximação das partículas (Kondo \& Dias Junior, 1999a; Silva et al., 2002; Oliveira et al., 2003; Silva et al., 2003; Silva \& Cabeda, 2006).

O solo sob MATA apresenta menor CSC na profundidade de $0-3 \mathrm{~cm}$, em relação a todos os sistemas de manejo de plantas invasoras utilizados na lavoura cafeeira (Figura 4), em virtude da ausência de ação antrópica e história de tensão.
Já para o solo sob os manejos SCAP e ENRT a menor CSC possivelmente pode ser atribuída aos menores valores de densidade do solo para o solo sob SCAP (Quadro 2) e à desagregação da camada superficial proporcionada pelo manejo ENRT, o que induz menor contato entre as partículas primárias, promovendo menor CSC em conteúdos elevados de umidade.

Para o solo sob o manejo ENRT, à conformação do equipamento e sua ação no solo, esperam-se maiores incrementos na CSC nas profundidades abaixo de $10 \mathrm{~cm}$, profundidade de trabalho do equipamento, agravando o grau de compactação em profundidade, como ressaltado por Kurachi \& Silveira (1984).

Pelos dados do quadro 6, observa-se que, quando o manejo de plantas invasoras foi realizado com a CAPM e GRAD e HPOS e ENRT e SCAP, os modelos de CSC foram iguais na profundidade de $10-13 \mathrm{~cm}$. Assim, uma nova equação foi ajustada, considerando todos os valores de pressão de preconsolidação e umidade (Figura 5).

O solo sob MATA apresenta menor CSC na profundidade de $10-13 \mathrm{~cm}$, em relação a todos os sistemas de manejo de plantas invasoras empregados na lavoura cafeeira (Figura 5). A menor CSC para o LVdf sob MATA está relacionada ao menor valor de densidade do solo (Quadro 2).

O manejo das plantas invasoras com ROCA proporciona maior CSC ao LVdf até a umidade volumétrica de $0,20 \mathrm{~cm}^{3} \mathrm{~cm}^{-3}$. Para umidades volumétricas superiores a $0,20 \mathrm{~cm}^{3} \mathrm{~cm}^{-3}$, a CSC do LVdf manejado com ROÇA reduz drasticamente na profundidade de 10-13 cm, em comparação ao solo sob os demais sistemas de manejo de plantas invasoras e

Quadro 6. Teste de significância ${ }^{(1)}$ entre os modelos de capacidade de suporte de carga ${ }^{(2)}$ de um Latossolo Vermelho distroférrico para os diferentes usos e manejo de plantas invasoras, para a profundidade de 10-13 cm, no centro das entrelinhas dos cafeeiros

Usos/manejo de plantas invasoras

\begin{tabular}{lc}
\multicolumn{2}{c}{$\mathrm{F}$} \\
\hline $\begin{array}{l}\text { Coeficiente } \\
\text { angular, b }\end{array}$ & $\begin{array}{c}\text { Intercepto da } \\
\text { regressão, a }\end{array}$
\end{tabular}

Capina manual us grade

Capina manual e grade $v s$ herbicida de pós-emergência

Capina manual e grade e herbicida de pós-emergência vs enxada rotativa

Capina manual e grade e herbicida de pós-emergência

rotativa $v s$ sem capina

Capina manual e grade e herbicida de pós-emergência e enxada rotativa e sem capina $v s$ herbicida de pré-emergência

Capina manual e grade e herbicida de pós-emergência e enxada rotativa e sem capina $v s$ roçadora

Capina manual e grade e herbicida de pós-emergência e enxada rotativa e sem capina us mata nativa

Roçadora vs herbicida de pré-emergência

Roçadora vs mata nativa

Mata nativa $v s$ herbicida de pré-emergência

\section{Profundidade $10-13 \mathrm{~cm}$}

$\mathrm{H}$

$\mathrm{H}$

$\mathrm{H}$

$\mathrm{H}$

$\mathrm{NH}$

$\mathrm{H} \quad * *$

$\mathrm{H}$

$\mathrm{NH}$

$\mathrm{H}$

$\mathrm{H}$

$\begin{array}{cc}\mathrm{ns} & \mathrm{ns} \\ \mathrm{ns} & \mathrm{ns} \\ \mathrm{ns} & \mathrm{ns} \\ \mathrm{ns} & \mathrm{ns} \\ * * & \mathrm{~ns} \\ & \\ * * & \mathrm{~ns} \\ & \\ & * * \\ * * & \\ * * & \mathrm{~ns} \\ \mathrm{~ns} & \mathrm{~ns} \\ & * *\end{array}$

\footnotetext{
(1) Snedecor \& Cochran (1989). ${ }^{(2)} \sigma_{\mathrm{p}}=10^{(\mathrm{a}+\mathrm{b} \theta)}$; NH: não homogêneo; H: homogêneo; **; *; ns: significativo a 1 e 5 \%; não significativo, respectivamente.
} 


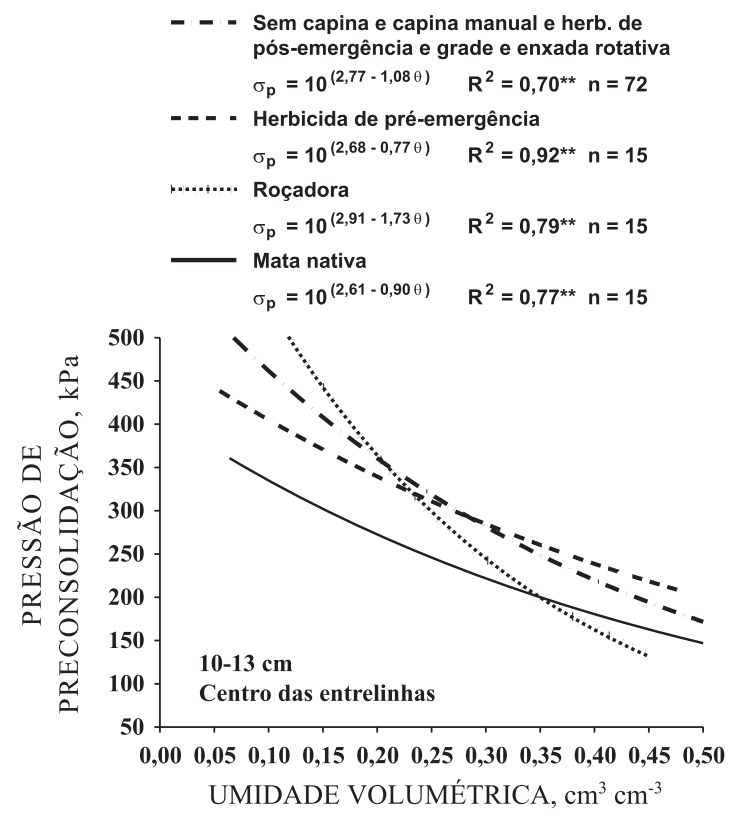

Figura 5. Modelos de capacidade de suporte de carga para um Latossolo Vermelho distroférrico sob mata nativa e cultivado com cafeeiros, submetido a diferentes sistemas de manejo de plantas invasoras na posição de amostragem centro das entrelinhas dos cafeeiros, na profundidade de $10-13 \mathrm{~cm}$.

ao solo sob MATA. Resultados semelhantes foram obtidos por Kurachi \& Silveira (1984), os quais observaram que o manejo de plantas invasoras com a roçadora foi o que proporcionou maior resistência mecânica ao solo nas umidades de 0,$15 ; 0,20 ; 0,21$; e
$0,23 \mathrm{~cm}^{3} \mathrm{~cm}^{-3}$, quando comparado aos manejos com capina manual, herbicidas, grade e enxada rotativa.

Os manejos SCAP e CAPM e GRAD e ENRT e HPOS; HPRE proporcionam comportamento intermediário quanto à CSC ao LVdf em umidades volumétricas inferiores a $0,20 \mathrm{~cm}^{3} \mathrm{~cm}^{-3}$, quando comparados aos manejos ROÇA e MATA (Figura 5).

Para umidades superiores a $0,30 \mathrm{~cm}^{3} \mathrm{~cm}^{-3}$, o manejo HPRE proporciona maior CSC ao LVdf (Figura 5). Esse comportamento está associado aos elevados valores de densidade do solo obtidos para o LVdf sob o manejo HPRE, na profundidade de 10$13 \mathrm{~cm}$ (Quadro 2).

Quando o manejo de plantas invasoras foi realizado com a MATA e SCAP; CAPM e GRAD; ROÇA e ENRT; e HPOS e HPRE, os modelos de CSC foram iguais na profundidade de 25-28 cm (Quadro 7). Assim, uma nova equação foi ajustada a cada conjunto de dados, considerando todos os valores de pressão de preconsolidação e umidade (Figura 6).

$\mathrm{Na}$ figura 6, observa-se que o manejo SCAP proporciona a mesma CSC quando comparado ao solo sob MATA, demonstrando não haver efeitos deste manejo no LVdf, na profundidade de $25-28 \mathrm{~cm}$. Por outro lado, observa-se que os métodos mecânicos (CAPM, ROÇA, GRAD e ENRT) e químicos (HPRE e HPOS) utilizados no manejo de plantas invasoras na lavoura cafeeira proporcionam aumentos na CSC em relação ao solo sob mata nativa (Figura 6).

O solo sob MATA e sob o manejo SCAP apresentam menor CSC até a umidade volumétrica de $0,38 \mathrm{~cm}^{3} \mathrm{~cm}^{-3}$, a partir da qual os manejos ROÇA e

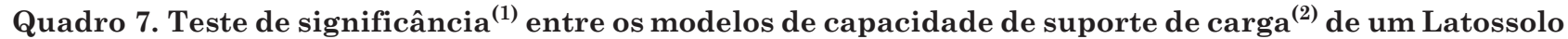
Vermelho distroférrico para os diferentes usos e manejo de plantas invasoras, para a profundidade de 25-28 cm, no centro das entrelinhas dos cafeeiros

Usos/manejo de plantas invasoras

\section{F}

\begin{tabular}{lc}
\multicolumn{2}{c}{$F$} \\
\hline $\begin{array}{l}\text { Coeficiente } \\
\text { angular, b }\end{array}$ & $\begin{array}{c}\text { Intercepto da } \\
\text { regressão, } a\end{array}$
\end{tabular}

Mata nativa $v$ sem capina

Capina manual us grade

Roçadora us enxada rotativa

Herbicida de pós-emergência vs herbicida de pré-emergência

Mata nativa e sem capina us capina manual e grade

Mata nativa e sem capina us roçadora e enxada rotativa

Mata nativa e sem capina vs herbicida de pós-emergência e

herbicida de pré-emergência

Capina manual e grade $v$ s roçadora e enxada rotativa

Capina manual e grade $v s$ herbicida de pós-emergência

e herbicida de pré-emergência

Roçadora e enxada rotativa us herbicida de pós-emergência

e herbicida de pré-emergência
Profundidade $25-28 \mathrm{~cm}$

$\begin{array}{lcc}\mathrm{H} & \mathrm{ns} & \mathrm{ns} \\ \mathrm{H} & \mathrm{ns} & \mathrm{ns} \\ \mathrm{H} & \mathrm{ns} & \mathrm{ns} \\ \mathrm{H} & \mathrm{ns} & \mathrm{ns} \\ \mathrm{H} & \mathrm{ns} & * * \\ \mathrm{H} & \mathrm{ns} & * * \\ \mathrm{H} & * & * * \\ \mathrm{H} & & \\ \mathrm{NH} & * * & * \\ \mathrm{H} & * & \mathrm{~ns}\end{array}$

\footnotetext{
(1) Snedecor \& Cochran (1989). ${ }^{(2)} \sigma_{\mathrm{p}}=10^{(\mathrm{a}+\mathrm{b} \theta)}$; NH: não homogêneo; H: homogêneo; **, *: significativo a 1 e 5 \%; ns: não
} significativo, respectivamente. 

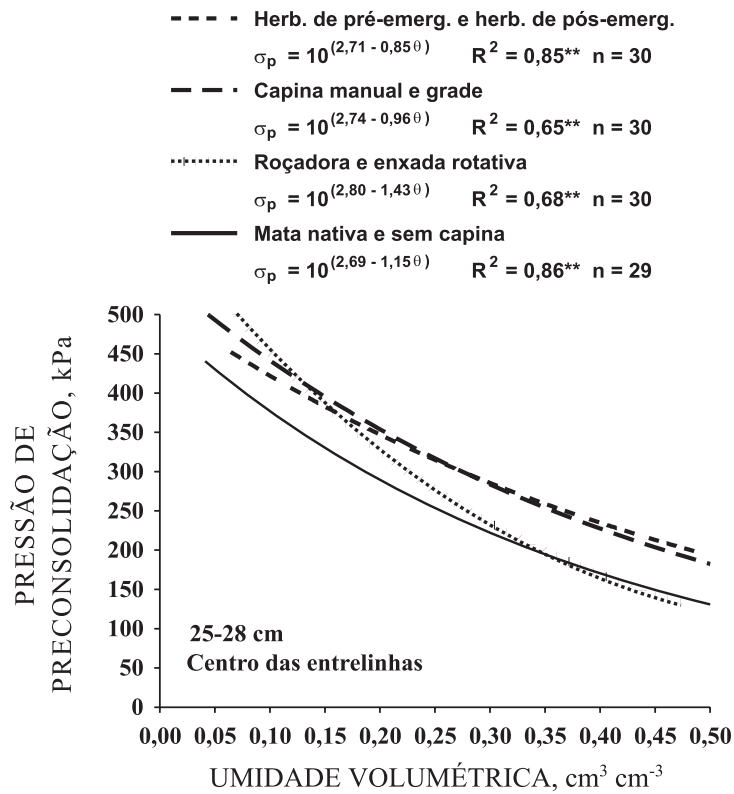

Figura 6. Modelos de capacidade de suporte de carga para um Latossolo Vermelho distroférrico sob mata nativa cultivado com cafeeiros e submetido a diferentes sistemas de manejo de plantas invasoras na posição de amostragem centro das entrelinhas dos cafeeiros, na profundidade de 25-28 cm.

ENRT apresentam a menor CSC (Figura 6). Para umidades volumétricas abaixo de $0,30 \mathrm{~cm}^{3} \mathrm{~cm}^{-3}$, o solo sob os manejos ROÇA e ENRT apresentam maior CSC em relação a todos os sistemas de manejo de plantas invasoras utilizados no solo sob a lavoura cafeeira e sob o solo de MATA. Para umidades volumétricas entre 0,10 e $0,30 \mathrm{~cm}^{3} \mathrm{~cm}^{-3}$, o solo sob os manejos CAPM e GRAD apresenta maior CSC em relação aos manejos ROCA e ENRT; HPOS e HPRE (Figura 6). Quanto a umidades volumétricas maiores que $0,30 \mathrm{~cm}^{3} \mathrm{~cm}^{-3}$, o solo sob os manejos HPOS e HPRE apresenta maior CSC em relação aos demais manejos de plantas invasoras e ao solo sob MATA, e o solo manejado com ROÇA apresenta a mesma CSC, quando comparado ao solo sob MATA, indicando não haver efeito deste manejo na profundidade de $25-28 \mathrm{~cm}$, no centro das entrelinhas dos cafeeiros (Figura 6). Kurachi \& Silveira (1984) observaram menor resistência mecânica do solo manejado com a roçadora, em comparação ao solo sob capina manual, nas profundidades maiores que $22 \mathrm{~cm}$, na umidade de $0,23 \mathrm{~cm}^{3} \mathrm{~cm}^{-3}$.

\section{CONCLUSÕES}

1. A tensão máxima aplicada pelo trator Valmet ${ }^{\circledR}$ 68 cafeeiro foi de $220 \mathrm{kPa}$ para o pneu dianteiro 6-16 na pressão de inflação de $172 \mathrm{kPa}$.

2. O menor valor de umidade crítica foi de $0,27 \mathrm{~cm}^{3} \mathrm{~cm}^{-3}$ para o Latossolo Vermelho distroférrico sob o manejo sem capina na profundidade de $0-3 \mathrm{~cm}$, e o maior valor, de $0,48 \mathrm{~cm}^{3} \mathrm{~cm}^{-3}$ para o solo sob o manejo herbicida de pré-emergência na profundidade de $0-3 \mathrm{~cm}$.

3. O solo sob mata nativa apresenta menor capacidade de suporte de cargas nas três profundidades estudadas, em relação ao solo cultivado com cafeeiros e submetido a diferentes manejos de plantas invasoras.

4. O manejo de plantas invasoras utilizando grade e herbicida de pré-emergência favorece a formação do encrostamento superficial e o incremento dos valores de densidade do solo e capacidade de suporte de carga na profundidade de $0-3 \mathrm{~cm}$.

5. Os diferentes manejos de plantas invasoras utilizados no centro das entrelinhas da lavoura cafeeira não influenciaram a densidade do solo e o teor de C orgânico do Latossolo, na profundidade de $25-28 \mathrm{~cm}$, em relação ao solo sob mata nativa.

\section{AGRADECIMENTOS}

Os autores agradecem ao Consórcio Brasileiro de Pesquisa e Desenvolvimento do Café CBP\&D/Café o apoio financeiro para o desenvolvimento do presente estudo. Aos funcionários da Fazenda Experimental da EPAMIG em São Sebastião do Paraíso - MG, especialmente a Paulo Guido de Azevedo, Homero José Lemos, Antônio Eguimar Pereira Xavier e Juracy Júnior de Oliveira, os quais contribuíram para a realização deste trabalho. $\mathrm{O}$ primeiro autor agradece à CAPES a concessão da bolsa de doutorado.

\section{LITERATURA CITADA}

ALAKUKKU, L.; WEISSKOPF, P.; CHAMEN, W.C.T.; TIJINK, F.G.J.; van der LINDEN, J.P.; PIRES, S.; SOMMER, C. \& SPOOR, G. Prevention strategies for field traffic-induced subsoil compaction: A review. Part I - Machine/soil interactions. Soil Tillage Res., 73:145-160, 2003.

ALCÂNTARA, E.N. \& FERREIRA, M.M. Efeito de métodos de controle de plantas daninhas na cultura do cafeeiro (Coffea arabica L.) sobre a qualidade física do solo. R. Bras. Ci. Solo, 24:711-721, 2000.

ARAUJO-JUNIOR, C.F.; DIAS JUNIOR, M.S.; GUIMARÃES, P.T.G. \& PIRES, B.S. Resistência à compactação de um Latossolo cultivado com cafeeiro, sob diferentes sistemas de manejos de plantas invasoras. R. Bras. Ci. Solo, 32:25$32,2008$.

BLAKE, G.R. \& HARTGE, K.H. Bulk density. In: KLUTE, A., ed. Methods of soil analysis. 2.ed. Madison, ASA/SSSA 1986. Part 1. p.363-375.

BOWLES, J.E. Engineering properties of soils and their measurements. 3.ed. New York, McGraw-Hill, 1986. 218p. 
CORREAA, S.; REETZ, E.R.; SANTOS, C.; SILVEIRA, D.; CARVALHO, C. \& BELING, R.R. Café do amanhã. In: BELING, R.R., ed. Anuário Brasileiro do Café. Santa Cruz do Sul, Gazeta Santa Cruz, 2009. 128p.

CRUZ, P.T. \& SAES, J.L. Mecânica dos solos. Editora Grêmio Politécnico, 1989. 192p.

DEXTER, A.R. Soil physical quality Part I. Theory, effects of soil texture, density, and organic matter, and effects on root growth. Geoderma, 120:201-214, 2004.

DAY, P.R. Particle fractionation and particle-size analysis. In: BLACK, C.A., ed. Methods of soil analysis. Madison, America Society of Agronomy, 1965. Part I. p.545-567.

DIAS JUNIOR, M.S. Compactação do solo. In: NOVAIS, R.F.; ALVAREZ V., H.V. \& SCHAEFER, C.E.G.R. Tópicos em ciência do solo. Viçosa, MG, Sociedade Brasileira de Ciência do Solo, 2000. v.1. p.55-94.

DIAS JUNIOR, M.S. Compression of three soils under longterm tillage and wheel traffic. East Lansing, Michigan State University, 1994.114p. (Tese de Doutorado)

DIAS JUNIOR, M.S. \& PIERCE, F.J. A simple procedure for estimating preconsolidation pressure from Soil compression curves. Soil Technol., 8:139-151, 1995.

DIAS JUNIOR, M.S. \& PIERCE, F.J. Revisão de literatura. O processo de compactação do solo e sua Modelagem. R. Bras. Ci. Solo, 20:175-182, 1996.

DISERENS, E. TASC - Tyres/Tracks and soil compaction. A pratical tool to prevent soil compaction damage. MS Excel 2000 FAT 2005/ Manual. 68p.

EMPRESA BRASILEIRA DE PESQUISA AGROPECUÁRIA EMBRAPA. Centro Nacional de Pesquisas de Solos. Manual de métodos de análises do solo. 2.ed. Brasília, Produção de informação, 1997. 212p.

EMPRESA BRASILEIRA DE PESQUISA AGROPECUÁRIA EMBRAPA. Centro Nacional de Pesquisas de Solos. Sistema brasileiro de classificação de solos. 2.ed. Rio de Janeiro, Embrapa Solos, 2006. 306p.

FARIA, J.C.; SCHAEFER, C.E.R.; RUIZ, H.A. \& COSTA, L.M. Effects of weed control on physical and micropedological properties of brazilian Ultisol. R. Bras. Ci. Solo, 22:731$741,1998$.

FERREIRA, D.F. Análises estatísticas por meio do SISVAR para Windows 4. 0. In: REUNIÃO ANUAL DA REGIÃO BRASILEIRA DA SOCIEDADE INTERNACIONAL DE BIOMETRIA, 45., São Carlos, 2000. Anais. São Carlos, UFSCAR, 2000. p.255-258.

GONTIJO, I.; DIAS JUNIOR, M.S.; GUIMARÃES, P.T.G. \& ARAUJO-JUNIOR, C.F. Atributos físico-hídricos de um Latossolo de cerrado em diferentes posições de amostragem na lavoura cafeeira. R. Bras. Ci. Solo, 32:2227-2234, 2008.

GROHMANN, F. \& RAIJ, B.van. Dispersão mecânica e prétratamento para análise granulométrica de Latossolos argilosos. R. Bras. Ci. Solo, 1:52-53, 1977.
HORN, R.; VOSSBRINK, J. \& BECKER, S. Modern forestry vehicles and their impacts on soil physical properties. Soil Till. Res.,79:207-219, 2004.

KONDO, M.K. \& DIAS JUNIOR, M.S. Compressibilidade de três Latossolos em função da umidade e uso. R. Bras. Ci. Solo, 23:211-218, 1999a.

KONDO, M.K. \& DIAS JUNIOR, M.S. Efeito do manejo e da umidade no comportamento compressivo de três Latossolos. R. Bras. Ci. Solo, 23:497-506, 1999b.

KURACHI, S.A.H. \& SILVEIRA, G.M. Compactação do solo em cafezal provocada por diferentes métodos de cultivo. Campinas, Instituto Agronômico de Campinas, 1984. 28p.

LARSON, W.E.; GUPTA, S.C. \& USECHE, R.A. Compression of agricultural soil from eight soil orders. Soil Sci. Soc. Am. J., 44:450-457, 1980.

LEBERT, M.; BÖKEN, H. \& GLANTE, F. Soil compaction indicators for assessment of harmful changes to the soil in the context of the German Federal Soil Protection Acta J. Environ. Manag., 82:388-397, 2007.

OLIVEIRA, G.C.; DIAS JUNIOR, M.S.; RESCK, D.V.S. \& CURI, N. Alterações estruturais e comportamento compressivo de um Latossolo Vermelho distrófico argiloso sob diferentes sistemas de uso e manejo. Pesq. Agropec. Bras., 38:291-299, 2003.

PAGLIAI, M. Soil structure. Trieste, College on Soil Physics, International Centre for Theoretical Physics, 2007. 27p. (Lecture Notes)

PENG, X.H.; HORN, R.; ZHANG, B. \& ZAHO, Q.G. Mechanisms of soil vulnerability to compaction of homogenized and recompacted Ultisols. Soil Till. Res.,76:125-137, 2004.

REICHERT, J.M.; REINERT, D.J. \& BRAIDA, J.A. Manejo, qualidade do solo e sustentabilidade: Condições físicas do solo agrícola. In: CONGRESSO BRASILEIRO DE CIÊNCIA DO SOLO, 29., Ribeirão Preto, 2003. Anais. Ribeirão Preto, SBCS, 2003. CD ROM.

RESENDE, M. \& SANTANA, D.P. Uso das relações Ki e Kr na estimativa da mineralogia para classificação de Latossolos. In: REUNIÃO DE CLASSIFICAÇÃO, CORRELAÇÃO DE SOLOS E INTERPRETAÇÃO DA APTIDÃO AGRÍCOLA, 3., Rio de Janeiro, 1988. Anais. Rio de Janeiro, Embrapa/ SNLCS/SBCS, 1988. p.225-232.

SEVERIANO, E.C.; OLIVEIRA, G.C.; DIAS JUNIOR, M.S.; OLIVEIRA, L.F.C. \& CASTRO, M.B. Pressão de preconsolidação e intervalo hídrico ótimo como indicadores de alterações estruturais de um Latossolo e de um Cambissolo sob cana-de-açúcar. R. Bras. Ci. Solo, 32:1419$1427,2008$.

SILVA, A.J.N. \& CABEDA, M.S.V. Compactação e compressibilidade do solo sob sistemas de manejo e níveis de umidade. R. Bras. Ci. Solo, 30:921-930, 2006.

SILVA, C.L. \& KATO, E. Efeito de selamento superficial na condutividade hidráulica saturada da superfície de um solo sob cerrado. Pesq. Agropec. Bras., 32:213-220, 1997. 
SILVA, R.B.; DIAS JUNIOR, M.S.; SILVA, F.A.M. \& FOLE, S.M. O trafego de máquinas agrícolas e as propriedades físicas, hídricas e mecânicas de um Latossolo dos cerrados. R. Bras. Ci. Solo, 27:973-983, 2003.

SILVA, V.R.; REINERT, D.J.; REICHERT, J.M. \& SOARES, J.M. Fatores controladores da compressibilidade de um Argissolo Vermelho-Amarelo distrófico arenico e de um Latossolo Vermelho distrófico típico. I: Estado inicial de compactação. R. Bras. Ci. Solo, 26:1-8, 2002.

SMITH, R.; ELLIES, A. \& HORN, R. Modified Boussinesq's equations for nonuniform tire loading. J. Terramech., 37:207-222, 2000.

SNEDECOR, G.W. \& COCHARAN, W.G. Statical methods. 8.ed. Ames, Iowa State University Press, 1989.

SOANE, B.D. The role of organic matter in soil compactabilty: A review of some practical aspects. Soil Till. Res.,16:179$201,1990$.

TAYLOR, D.W. Fundamentals of soil mechanics. New York, John Wiley, 1948. 770p.

TIMM, L.C.; PIRES, L.F.; REICHARDT, K.; ROVERATTI, R.; OLIVEIRA, J.C.M. \& BACCHI, O.O.S. Soil bulk density evaluation by conventional and nuclear methods. Austr. J. Soil Res., 43:97-103, 2005.
TIMM, L.C.; PIRES, L.F.; ROVERATTI, R.; ARTHUR, R.C.J.; REICHARDT, K.; OLIVEIRA, J.C.M. \& BACCHI, O.O.S. Field spatial and temporal patterns of soil water content and bulk density changes. Sci. Agric., 63:55-64, 2006.

van den AKKER, J.J.H. \& SOANE, B. Compaction. In: HILLEL, D.; ROSENZWEIG, C.; POWLSON, D.; SCOW, K.; SINGER, M. \& SPARKS, D. eds., Encyclopedia of soils in the environment. New York, Academic, 2005. v.1. p.285293.

WALKLEY, A. \& BLACK, I.A. An examination of the Degtjareff method for determining soil organic matter and a proposed modification of the chromic acid titration method. Soil Sci., 37:29-38, 1934.

YANG, Y.; WANG, H.; TANG, J. \& CHEN, X. Effects of weed management practices on orchard soil biological and fertility properties in southeastern China. Soil Till. Res., 93:179-185, 2007.

ZHANG, B.; HORN, R. \& HALLET, P.D. Mechanical resilience of degraded soil amended with organic matter. Soil Sci. Soc. Am. J., 69:864-871, 2005.

ZHANG, H.; HARTGE, K.H. \& RINGE, H. Effectiveness of organic matter incorporation in reducing soil compactibility. Soil Sci. Soc. Am. J., 61:239-245, 1997. 